\title{
Un escultor para un cardenal. Lorenzo Mercadante de Bretaña y el sepulcro de Juan de Cervantes: nuevas lecturas documentales
}

\author{
A sculptor for a cardinal. Lorenzo Mercadante de Bretaña's \\ sepulcre for Juan de Cervantes: \\ new approaches to documentary evidence
}

Teresa LAGUNA PAÚL

Universidad de Sevilla

Recibido: 15-IV-2017

Aceptado: 13-VI-2017

RESUMEN: La investigación aporta nueva información de los trabajos de Mercadante de Bretaña en la capilla de san Hermenegildo de la catedral de Sevilla en 1453-1454: el bulto del cardenal Juan de Cervantes y una imagen de la Virgen talladas en alabastro. Reconstruye documentalmente y da a conocer una etapa inédita del primer altar y del enterramiento temporal de este prelado, desarrolla una hipótesis relativa al acuerdo para la realización del sepulcro del cardenal promovido con su legado y realizado por este escultor.

Palabras clave: Lorenzo Mercadante de Bretaña, Lorenzo Mercader, Escultura gótica, Escultura funeraria, Juan de Cervantes, Catedral de Sevilla

ABSTRACT: Recent research has cast new light on two of Mercadante de Bretaña's works at Saint Hermenegild's chapel, within Seville's cathedral, in 1453-1454, namely, the statues of cardinal Juan de Cervantes and the Virgin Mary, both carved in alabaster. The documentary evidence available allows for a reconstruction of the altar, in its first, hitherto unknown phase, the cardinal's temporary burial place, hypothesis concerning the agreement for the realization of the sepulchre, built by the aforementioned sculptor at the cardinal's own expenses.

Keywords: Lorenzo Mercadante de Bretaña, Lorenzo Mercader, Tomb sculpture, Funeral statuary, Juan de Cervantes, Seville's cathedral

El 25 de noviembre de 1453 falleció en las casas arzobispales, localizadas en el muro meridional de la catedral detrás de la capilla de la Antigua, el cardenal Don Juan de Cervantes y Bocanegra, obispo de OstiaVelletri desde 1446 y administrador apos- tólico de la diócesis de Sevilla, quien fundó la capilla de san Hermenegildo en 1451 en la catedral de Sevilla y dejó a la Fábrica de esta seo como su heredera universal ${ }^{1}$. Con su

${ }^{1}$ Grupo de investigación Laboratorio de Arte (HUM210). El presente artículo se ha elaborado en el marco 
legado testamentario concluyeron las obras pendientes en la capilla, organizaron su ajuar litúrgico, dispusieron su retablo y su sepultura, una obra singular en la historia de la escultura española. Un monumento funerario de carácter internacional que, tanto por su promotor como por su artífice, estableció un recuerdo, una asociación perpetua entre el cardenal y su artífice. La inscripción funeraria, que rodea el paño bajo el cuerpo del prelado, exalta la bondad del difunto a cuya perpetua memoria se vinculó el escultor con su firma: "Lorenzo Mercadante de Bretaña entallo este bulto" (Fig. 1)

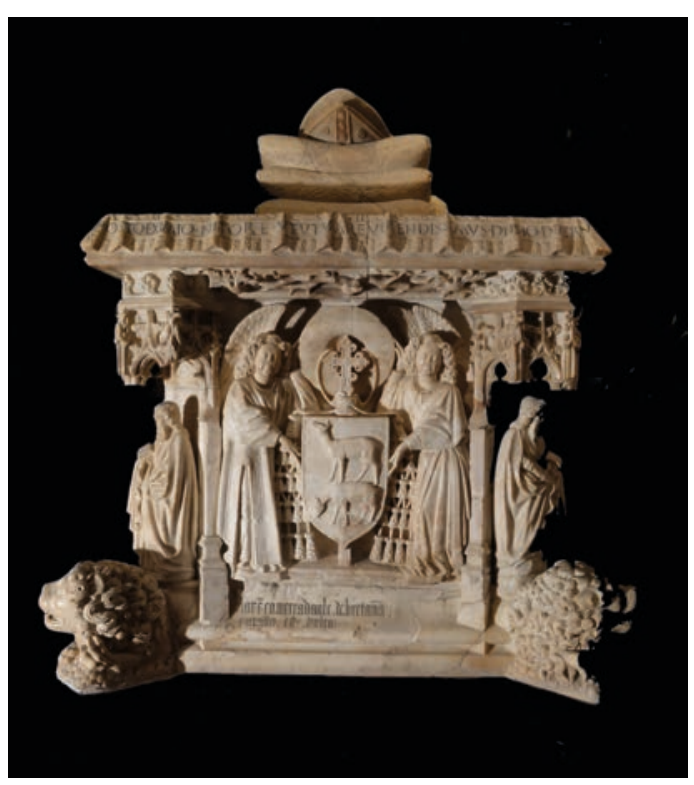

- Fig. 1. Cabecera del monumento funerario del cardenal Juan de Cervantes con la firma de Lorenzo Mercadante de Bretaña en el zócalo. 1453-1458. Catedral de Sevilla, capilla de san Hermenegildo. Foto de la autora.

Juan de Cervantes, vástago de una familia noble sevillana, nació en Lora del Río en 1382 y pronto destacó al servicio de la corona castellana y de la diplomacia pontificia. Su vida pública se desenvolvió en el campo de las relaciones y política eclesiástica; nunca escribió tratados de teología o jurispruden-

del proyecto El patronazgo artístico en el Reino de Castilla y León (1230-1500). Obispos y catedrales, (HAR201344536-R), financiado por el Ministerio de Economía y Competitividad y cofinanciado con fondos FEDER. cia pero su presencia siempre aparecía cuando era necesario un intermediario capaz de negociar entre posiciones encontradas.

Formado posiblemente en la universidad de Salamanca, Benedicto XIII le nombró arcediano de Calatrava en 1415 y estuvo en Peñíscola como procurador real de Catalina de Lancaster dos años después. Implicado personalmente en los grandes problemas eclesiásticos de su tiempo actuó en Florencia como parlamentario del rey castellano en la corte de Martín V, participó como miembro de la Natio Hispanica en el concilio de Pavía-Siena de 1423-1424 y en la resolución del Cisma de Occidente. Este pontífice confió plenamente en él, lo nombró cardenal de San Pedro ad Vincula en 1426 y le dio amplios poderes para presidir el capítulo de la orden franciscana de 1430 en Asís. Establecido en Roma, se rodeó de una corte que contó con destacados poetas, intelectuales y humanistas como Eneas Silvio Piccolomini (1405-1464), el futuro papa Pío II, que fue su secretario en el concilio de Basilea donde tuvo un papel destacado y llegó a ser llamado por sus compañeros "Iudex fidei". En 1431 participó activamente en el cónclave de la elección de Eugenio IV, quien lo designó su legado apostólico conciliar junto al cardenal Nicolás Albergati y lo premió con el arcedianato de Talavera en la iglesia de Toledo, aunque pronto tuvieron serias divergencias motivadas cuando éste decretó la disolución del concilio de Basilea, seis meses después de comenzar sus sesiones en 1431. El curso de los acontecimientos pontificios en 1435 dio un giro a su trayectoria en la política eclesiástica, que le llevó a abandonar definitivamente los asuntos conciliares y a volver a Castilla a comienzos de 1440, comisionado por Eugenio IV para actuar de mediador entre los bandos que litigaban por el poder en la monarquía².

2 Para una síntesis de su biografía: J. GOÑI GAZTAMBIDE, "Cervantes, Juan de", en Diccionario de Historia Eclesiástica de España, Suplemento I, Madrid, 1987, pp. 124-128; J. ALONSO MORGADO, Prelados sevillanos o episcopologio de la S.I.M. y P. de Sevilla, Sevilla, 1899-1904, pp. 352-353. J. A. OLLERO PINA, Juan de 
Desde su vuelta a Castilla intentó, sin éxito, ser arzobispo de Sevilla, ya que su larga ausencia nunca supuso una ruptura con la ciudad, ni con la catedral como evidencia su carta inédita y autógrafa dirigida a su Deán y Cabildo confirmándoles, el 11 de diciembre de 1439, las gestiones realizadas para sus asuntos pendientes en la corte ${ }^{3}$. En esta catedral debió mantener la dignidad del arcedianato de Sevilla, la segunda en importancia del cabildo, desde 1419 hasta su nombramiento como administrador apostólico de Ávila en marzo de 1440, cargo que permutó por el de Segovia con Fray Lope de Barrientos y legitimó Roma en julio de $1441^{4}$. El 7 de noviembre de 1446 se le asignó la sede de Ostia-Velletri, donde nunca tomó posesión pues a finales de aquel verano había emprendido, enfermo, su vuelta a Sevilla. La llegada del cardenal constituiría un acontecimiento en esta ciudad, un referente de la élite internacional conocedora de vanguardias $\mathrm{y}$ tendencias artísticas de la primera mitad del siglo $\mathrm{XV}$, de sus promotores y de algunos de sus artistas; un intelectual próximo para demandar opiniones, recabar informaciones y tomar buena nota para algunas empresas artísticas del cabildo e indudablemente de toda la diócesis.

Éste fue un viaje, un camino, sin retorno pero sin cesar en su influencia en la ciudad y en la diócesis ya que el abstencionismo del arzobispo García Enríquez Osorio lo convirtió en el eclesiástico de mayor influencia de la Iglesia de Sevilla. Al fallecer éste en 1448, el cabildo hispalense en sede vacante postuló su nombramiento para esta diócesis, pero el apoyo de Juan II a Rodrigo de Luna, su capellán mayor y sobrino de su privado el condestable Álvaro de Luna, así como el cur-

Cervantes (1382-1453), "el mayor perlado de mis Regnos", original en prensa.

${ }^{3}$ Archivo Catedral de Sevilla (en adelante ACSe), Fondo Histórico General, Caja 12092, № 58.

${ }^{4}$ J. HERRERA DÁVILA, El Hospital del cardenal de Sevilla y el doctor Hidalgo Agüero: visión histórico-sanitaria del Hospital de san Hermenegildo de Sevilla (1445-1837), Sevilla, 2010, pp. 42 y siguientes. so de los acontecimientos determinaron que, finalmente, el pontífice le nombrara Administrador apostólico perpetuo de la diócesis en la primavera de 1449. Juan de Cervantes ocupó este cargo y su gestión desde entonces y hasta su muerte el 25 de noviembre de 1453; durante estos años, trascendentales en la construcción de la catedral gótica de Sevilla tanto en los aspectos financieros de su fábrica como en la ejecución de los trabajos, situó entre los prebendados y cargos del cabildo a un alto número de sus familiares, realizó numerosas obras de caridad entre los necesitados, protegió a las órdenes religiosas, promovió la devoción a la santa Faz y al mártir san Hermenegildo, cuyas reliquias buscó sin éxito en esta misma ciudad.

\section{UN ESCULTOR PARA UN CARDE- NAL}

La inscripción “Lorenzo Mercadante de Bretaña entallo este bulto", tallada en el basamento del sepulcro, fue siempre visible y recogida por los historiadores sevillanos en sus obras manuscritas e impresas desde el siglo XVI. Antonio Ponz difundió en su Viaje de España la autoría del sepulcro y sus características, Juan Agustín Ceán Bermúdez incorporó a este escultor en su Diccionario histórico de los más ilustres profesores de Bellas Artes en España en 1800 y José Gestoso dio a conocer las primeras noticias documentales en $1890^{5}$. Este erudito investigador y archivero, que había consultado en septiembre de 1887 el libro de cuentas de la mayordomía de la catedral de 1454, publicó el finiquito del pago realizado a Lorenço Mercader por dos esculturas de alabastro que relacionó con una escultura de la virgen perdida y con el bulto de un túmulo que pensó sería uno desaparecido del arzobispo Don Juan de Cerezuela, e interpretó otro abono de un relie-

\footnotetext{
5 A. PONZ, Viage de España en que se da noticia de las cosas mas apreciables y dignas de saberse, que hay en ella, Madrid, 1786, vol. IX, pp. 20-21. J. A. CEÁN BERMÚDEZ, Diccionario histórico de los mas ilustres profesores de las bellas artes en España, Madrid, 1800, vol. III, pp. 133-134; ÍDEM, Descripción artística de la catedral de Sevilla, Sevilla, 1804, pp. 83-84.
} 


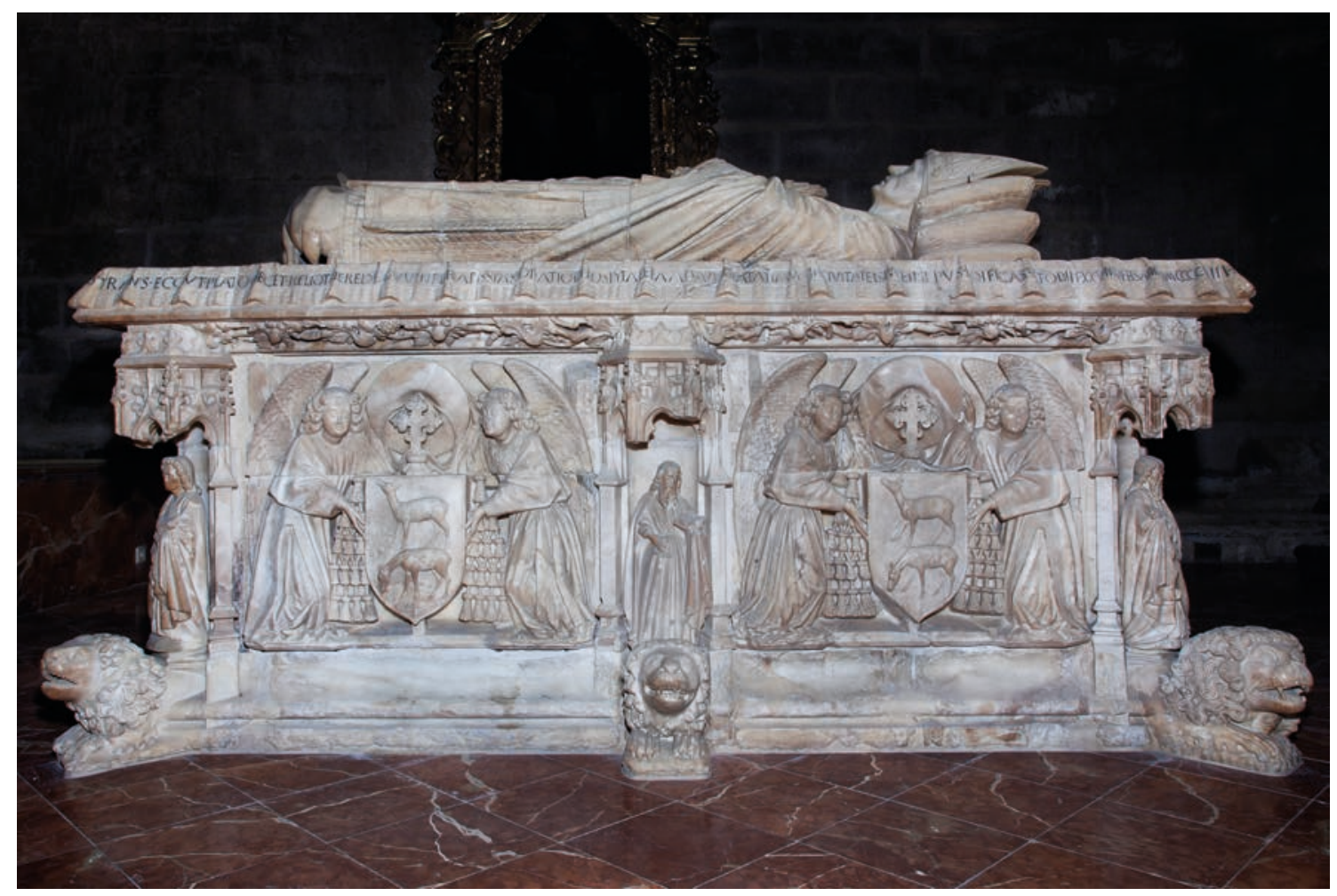

- Fig. 2. Lorenzo Mercader / Lorenzo Mercadante de Bretaña. Monumento funerario del cardenal Juan de Cervantes. 1453-1458. Catedral de Sevilla, capilla de san Hermenegildo. Foto de la autora.

ve en 1458 con los trabajos del sepulcro del cardenal Don Juan de Cervantes ${ }^{6}$. Manuel Gómez Moreno fue pionero en relacionar el bulto del cardenal con los pagos a Mercadante por las esculturas de barro cocido de la fachada occidental de la catedral e indicó que su nombre era una castellanización de "Lorens Marchand" o "Marc'hadaur"7. En 1928 Diego Angulo descartó definitivamente la hipótesis del pretendido bulto de Don Juan de Cerezuela, señaló que Mercadante únicamente talló en cuatro piezas de alabastro la escultura del cardenal Cervantes cuyos ornamentos vinculó con bordados eyckia-

6 J. GESTOSO y PÉREZ, Sevilla monumental y artística. Historia y descripción de todos los edificios notables, religiosos y civiles que existen actualmente en esta ciudad y noticia de las preciosidades artísticas y arqueológicas que en ellos se conservan, Sevilla, 1890, T. II, p. 520. ACSe, Sección IV Fábrica, Libro 9341(7), fol. 40v. y 72v. y Libro 9342(8), fol. 12v.

7 M. GÓMEZ MORENO, “¿Jooskén de Utrech, arquitecto y escultor?", Boletín de la Sociedad Castellana de Excursiones, V, 1911, pp. 63-66. nos, dató los trabajos del sepulcro entre 1453 y 1458 e identificó a la Virgen del Madroño con la imagen mariana abonada al mismo escultor en $1454^{8}$. Medio siglo más tarde Jacques Baudoin lo incluyó entre los grandes escultores itinerantes europeos, destacó en él un realismo de carácter borgoñón, analogías formales con la escultura bretona de la primera mitad del siglo XV y una síntesis formal motivada por su vida itinerante que impiden establecer filiaciones precisas respecto a su lugar de nacimiento o al taller donde realizara su aprendizaje (Fig. 2) ${ }^{9}$.

${ }^{8}$ D. ANGULO ÍÑIGUEZ, "Sepulcro del cardenal Cervantes en la catedral de Sevilla", en La Escultura en Andalucía, Sevilla, 1928, vol. I, Lams. 1-18, 44-58, cuaderno 1 y 5; ÍDEM, "Bordados de estilo eyckiano del sepulcro del cardenal Cervantes de la Catedral de Sevilla", Mélanges Hulin de Loo, 1931, pp. 1-4. H. STEGMANN y D. ANGULO, La escultura en Occidente, Barcelona, 1936, pp. 182-183.

9 J. BAUDOIN, "Destinées itinerantes des grands imaginiers de la fin du moyen âge", Francia. Forschungen zur westteuropäischen Geschichte, vol. 14, 1986 (1987), pp. 163-164. 
En 1987 Francisco Reina Giraldez publicó un pago a Lorenzo Mercader del 23 de marzo de 1454 por los gastos de su venida desde Francia para trabajar en la catedral. Esta noticia la recogió toda la historiografía posterior junto a otros pagos del mismo año que confirmaron la realización de sus primeras obras en esta seo: un bulto de alabastro del "arçobispo Don Juan" de Cervantes y otro de una imagen de la Virgen ${ }^{10}$. Desde entonces las investigaciones sobre este escultor se han centrado en sus obras de barro cocido aportando un conocimiento directo a las técnicas y etapas de confección de las esculturas de las portadas occidentales de la catedral sevillana, de las imágenes de culto encargadas para otros templos, monasterios y oratorios de los antiguos reinos de Sevilla y Córdoba ${ }^{11}$.

${ }^{10}$ ACSe, Sección IV Fábrica, Libro 9341(7), fol. 55v. F. REINA GIRÁLDEZ, "Llegada a Sevilla y primeras obras de Lorenzo Mercadante de Bretaña", Archivo Hispalense, no 215, 1987, pp. 143-151.

11 F. ARQUILlO TORRES, "El estado de conservación de las esculturas de Mercadante que decoran las portadas del bautismo y del nacimiento de la catedral de Sevilla", Atrio: revista de arte, no 2, 1990, pp. 145-158. C. CIRUJANO GUTIÉRREZ, "Proceso de intervención en las portadas del Nacimiento y del Bautismo de la catedral de Sevilla", Bienes Culturales, $\mathrm{n}^{-}$ 1, 2002, pp. 101-120. T. LAGUNA PAÚL, "Las portadas del Bautismo y del Nacimiento de la catedral de Sevilla", Bienes Culturales, Revista del Patrimonio Histórico Español, nº1, 2002, pp. 83-101; ÍDEM, “De la línea al volumen: génesis figurativa y modelos grabados en la obra de Lorenzo Mercadante de Bretaña", en Copia e invención. Modelos, réplicas, series y citas en la escultura europea, II Encuentro internacional de museos y colecciones de escultura, Valladolid, 2013, pp. 137-150; ÍDEM, “Marco arquitectónico y retórica visual en barro en la catedral de Sevilla", en B. ALONSO RUIZ y J.C. RODRÍGUEZ ESTEVEZ, Sevilla 1514. Arquitectos tardogóticos en la encrucijada, Sevilla, 2016, pp. 39-48. J. GONZALEZ CARAVALLO,"Escultura en Sevilla en tiempos de Siloé: una nueva obra para el catálogo", en J. YARZA y A. IBAÑEZ (coords.), Actas del Congreso Internacional sobre Gil Siloé y la Escultura de su época, 1999, Burgos, 2001, pp. 487-499; M. A. TEVA (coord..), Lorenzo Mercadante de Bretaña: La escultura del arcángel San Miguel: Sanlúcar la Mayor, Sevilla, 2007. M. A. MARTÍN SÁNCHEZ, El imaginero Lorenzo Mercadante. Estudio de la obra y claves de su huella en la Virgen de las Nieves de la Isla Canaria de la Palma, La Laguna-Tenerife, 2009. N. JENNINGS y T.
Recientemente Javier Ibáñez y Diego Domínguez dieron a conocer un contrato de aprendizaje y estancia de Lorenzo Mercader en el taller del escultor Fontaner de Usesques en Zaragoza, desde el 28 de abril de 1446 hasta el 29 de mayo de 1448, demostrando su presencia en la península Ibérica seis años antes de las fechas conocidas. Además la elevada remuneración concertada confirmó su condición de maestro escultor encubriendo un aprendizaje, un compromiso laboral que le permitió solventar la reglamentación gremial aragonesa, muy estricta con los profesionales formados fuera y a quienes podían exigir superar un examen, desembolsar una importante cantidad de dinero o efectuar una pasantía en un taller local antes de ejercer libremente en la capital del Ebro. Esta noticia permitió suponer una colaboración en alguno de los compromisos que tenía firmados el bearnés Usesques aquellos años: un retablo de la Natividad en alabastro concertado con el vicecanciller Juan de Funes para el convento de san Francisco de Zaragoza (1446-1448), la imagen titular del retablo de la Virgen Blanca de la seo zaragozana (1448) y las piedras armeras de la Casa de la Diputación del Reino (1447-1449), talladas en una piedra arenisca por dos manos diferentes. Igualmente, pudo entablar contacto o relaciones con otros canteros y escultores que habrían coincidido o trabajado con el equipo de profesionales extranjeros que labraron, simultáneamente, en la capilla de los Corporales de Daroca y en la de san Agustín de la seo de Zaragoza (1417-1422) donde intervinieron, entre otros, los maestros Isambarte y Carlín presentes una década después en la catedral de Sevilla y con el valenciano Antoni Dalmau documentado en la predela del retablo de la seo zaragozana y en otras empresas del arzobispo Dalmau de Mur ${ }^{12}$.

LAGUNA PAÚL, Lorenzo Mercadante de Bretaña. Virgen del Buen Fin, Madrid, 2016.

${ }^{12}$ J. IBÁÑEZ FERNÁNDEZ y D. DOMÍNGUEZ MONTERO, "Antes de Sevilla: Lorenzo Mercader (Mercadante) de Bretaña en Zaragoza (1446-1448). Transferencias e intercambios entre las Coronas de Aragón y Castilla a mediados del siglo XV", Artigrama, 
Su presencia en la capital del Ebro hace pensar que en 1446 tendría aproximadamente unos veinte años de edad, los mismos que el bretón Juan Guas cuando aparece documentado en la puerta de los Leones de la catedral de Toledo o los veintidós de Pedro Jalopa al firmar un contrato de aprendizaje durante seis años con Pere Torregosa en 1408, antes de iniciar su dilatada e itinerante trayectoria profesional por distintos reinos peninsulares $^{13}$. Esta hipótesis relativa a la previsible fecha de nacimiento de Lorenzo Mercader, avalaría una formación y primeros trabajos en Francia o en Bélgica anteriores a su presencia en el territorio hispano. Al fallecer el cardenal Juan de Cervantes y contratar con la catedral de Sevilla, su heredera, estas dos esculturas de alabastro era un maestro completamente maduro y con prestigio que, aquel invierno de 1453-1454, contaría unos veintisiete o treinta años si llegó a la capital aragonesa después de su periodo de formación; prácticamente la misma que el maestro Isambart cuando fue contratado como arquitecto de la catedral de Lérida ${ }^{14}$.

n⿳⺈ 30, 2015, pp. $169-191$.

${ }^{13}$ Para las edades y trayectorias de Jalopa, Juan Guas e Isambarte puede consultarse: J. VALERO MOLINA, "Pere Torregrosa, Pere Jalopa i la capella de san Sever de la catedral de Barcelona", Lambard. Estudis d'art medieval vol. XXI, 2010, pp. 172-175. J. IBÁÑEZ FERNÁNDEZ, "La arquitectura en el reino de Aragón entre el Gótico y el Renacimiento: inercias, novedades y soluciones propias", en M. I. ÁLVARO ZAMORA y J. IBÁÑEZ FERNÁNDEZ (coord.), La arquitectura en la Corona de Aragón entre el Gótico y el Renacimiento (14501550). Rasgos de unidad y diversidad, Zaragoza, 2009, pp. 48-52; ÍDEM, La capilla del palacio arzobispal de Zaragoza en el contexto de la renovación del Gótico final en la Península Ibérica, Zaragoza, 2012, pp. 17-18. J. BAUDOIN, Op. cit, pp. 164-165. A. YUSTE GALÁN, “La introducción del arte flamígero en Castilla: Pedro Jalopa, maestro de los Luna", Archivo Español de Arte, nº 307, LXXVI, 2004, pp. 293. A. SERRA DESFILIS, "Promotores, tradiciones e innovación en la arquitectura valenciana del siglo XV", Goya, nº 334, 2011, p. 236, nota 45. B. ALONSO RUIZ, "El maestro de obras catedralicio en Castilla en el siglo XV", Anales de Historia del Arte, no 22 especial, 2012, pp. 225-243.

${ }^{14}$ T. LAGUNA PAÚL, "The Virgen del Buen Fin in the context of the sculptural oeuvre of Lorenzo Mercadante de Bretaña", en N. JENNINGS y T.
La importancia del encargo, la calidad del monumento sepulcral del cardenal Juan de Cervantes, la valía profesional y las obras en barro cocido de Mercadante de Bretaña trascendieron en el panorama escultórico bajomedieval del reino de Sevilla. La historiografía le señala como el introductor de las formas franco-flamencas, eyckianas, en Andalucía y el maestro de otros escultores activos en la misma ciudad en el último tercio del siglo $\mathrm{XV}$, pero todavía se desconoce dónde pudo realizar su formación, quién o quiénes fueron sus ayudantes o sus oficiales mientras trabajó en la catedral de Sevilla donde está documentado como "maestre Lorenzo" o "Lorenço Mercader" durante catorce años, desde principios de 1454 hasta enero de 1468. Tradicionalmente le relacionan con la escuela de Borgoña aunque, a tenor de su procedencia, pudo formarse en Bretaña donde hubo una intensa actividad artística durante el gobierno del duque Juan VI el sabio (1389-1442) que dio lugar a una escuela de escultura monumental con especialistas en sepulcros cuyas obras mas representativas desaparecieron con la Revolución Francesa y mantienen su recuerdo por algunas descripciones, los dibujos de la colección Gaignières (Biblioteca Nacional de Francia y Pierpont Morgan Library) y los testimonios conservados ${ }^{15}$. Nicola Jennings, al destacar la importancia del escultor bretón en el contexto del panorama europeo del siglo $\mathrm{XV}$, lo cree originario de la diócesis de Saint-Pol-de-Lyon y propone identificarlo con el anónimo Maestro de Carlos de Artois, que talló hacia 1450 las efigies del monumento funerario de este conde (1394-1472) y su primera mujer Jeanne de Saveuse $(+1449)$ para la colegiata de Nuestra Señora y san Lorenzo de Eu (Normandía, Francia), a setenta kilómetros de la ciudad de Rouen ${ }^{16}$. Sus re-

LAGUNA, Op.cit., pp. 49-51.

15 T. LAGUNA PAÚL, "De la línea al volumen...", pp. 137-150; ÍDEM, “The Virgen del Buen Fin”, pp. 4756. J. BAUDOIN, La sculpture flamboyante en Normandie et Ile-de-France, Paris, 1993, pp. 181-185, 195-197 y 232325.

${ }^{16}$ N. JENNINGS, “Lorenzo Mercadante de Bretaña, 
flexiones abren un interesante interrogante respecto a la datación de este monumento francés cuyos elementos arquitectónicos son muy tradicionales y parecen anteriores a la fecha propuesta por la historiografía france$\mathrm{sa}^{17}$. Ciertos rasgos formales de la condesa tienen analogías con algunas esculturas en barro cocido de Mercadante que evidencian modelos comunes o una colaboración entre ambos maestros mas que una identificación de ellos, y suscitan una prudente cautela hasta que otras investigaciones documenten con mayor precisión la escultura francesa, se conozcan otros contratos o alguna remuneración de Mercadante en la península Ibérica desde mayo de 1448 hasta comienzos de 1454.

Durante estos seis años pudo volver a Francia y realizar algún encargo, aunque lo habitual entre los artistas extranjeros fue continuar su carrera profesional en la península Ibérica. En la Corona de Aragón, a tenor de la documentación conocida, algunos escultores como Guillen Sagrera o Rotllí Gautier trabajaron además en el Rosellón, la Cerdaña y en Nápoles, territorios vinculados históricamente a este reino ${ }^{18}$. En su trayectoria laboral, y antes de venir a Sevilla, Lorenzo

primus inter pares of Northern European sculptors in fifteenth-century Castille", en N. JENNINGS y T. LAGUNA, Op.cit., pp. 23 y 30-31 indica un posible nacimiento de Mercadante de Bretaña en la diócesis de Saint-Pol-de-Lyon según el trabajo de J. C. CASSARD, “Un Valencien en Bretagne au XVe siècle: Vincent Férier (1418-1419), 3n HAL France p. 167, consultado el 18 de septiembre de 2016. URL: http://hal.univ-brest.fr/hal00439427, que, sin embargo, omite cualquier referencia sobre el particular.

${ }^{17}$ J. BAUDOIN, La sculpture flamboyante..., pp. 183184.

18 F. ESPAÑOL BERTRÁN, "El artífice y sus habilidades. La transmisión del conocimiento artístico medieval", en M. MIQUEL, O. PÉREZ MONZON y M. BUESO, Ver y crear. Obradores y mercados pictóricos en la España gótica (1350-1500), Madrid, 2016, pp. 98-134. Para Rotllí Gautier: V. D. LÓPEZ LORENTE, “Las 'mostres imayges e empints de Rotllí Gautier (doc. 1392-1441) y su importancia en la transmisión del conocimiento artístico", en B. ALONSO RUIZ y J. C. RODRÍGUEZ ESTÉVEZ, Arquitectos tardogóticos en la encrucijada, Sevilla, 2016, pp. 79-89.
Mercader llevaría a cabo algún encargo eclesiástico o para la influyente nobleza castellana, quizás pudo contactar con colaboradores de Pedro Jalopa, quien había sido el "pedrero mayor de la capilla del Condestable, Don Álvaro de Luna" (1433-1438) en la catedral de Toledo y cinco años más tarde asumió la maestría de la catedral de Palencia con Gómez Díaz ${ }^{19}$. Tampoco debe descartarse una estancia en la diócesis de Toledo, en cuya catedral trabajaron otros canteros, entalladores y escultores foráneos bajo la dirección del maestro Hanequin de Bruselas y considerar que, durante estos años, mantendría contactos con los maestros que habría conocido en el reino aragonés, con otros contemporáneos $\mathrm{y}$, especialmente, con aquellos cuya trayectoria profesional llevó los modelos de la arquitectura tardogótica hasta el valle del Guadalquivir: algún colaborador del flamenco Isambart, del bretón Charles Gauter de Rúan o del valenciano Antoni Dalmau cuya valía profesional había llamado la atención del cardenal Juan de Cervantes.

Desconocemos todavía qué obras talló o modeló, en qué localidades estuvo o qué encargos llevó a cabo desde el 29 de mayo de 1448, cuando liquidó su contrato con Fontaner de Usesques, hasta el día 16 de enero de 1454 en que los contadores de la catedral de Sevilla le abonaron una cantidad de 400 maravedíes "a cuenta de las obras que hace" y sesenta y seis días después otra de 600 maravedís "para la costa porque vino por su llamada desde Françia por una carta suya para que labrase en la yglesia". Francisco Reina relacionó este pago del 23 de marzo con la fecha de la llegada de Mercadante desde su lugar de origen e interpretó la primera como un error o una anotación de la contabilidad correspondiente a enero de $1455^{20}$. No obstante este abono corresponde a la primera

${ }^{19}$ A. YUSTE GALÁN, Op.cit, p. 293. R. MARTÍNEZ, “Gómez Díaz de Burgos (1430-1466), maestro mayor de la obra de la catedral de Palencia", Publicaciones de la Institución Tello Téllez de Meneses, no 58, 1988, pp. 418 y 422 , doc 3 .

${ }^{20}$ ACSe, Sección IV Fábrica, Libro 9341(7), fol. 71v. y 55v. F. REINA GIRÁLDEZ, Op.cit., pp. 143-144 y 149. 
de otras once remuneraciones cobradas a cuenta en 1454 por un contrato concertado el año anterior, aunque la falta de documentación de 1452 y 1453 impide precisar cómo y en qué momento Lorenzo Mercader establecería los primeros contactos con el cardenal Juan de Cervantes o con la catedral de Sevilla. Los vacíos del archivo de la catedral hispalense entre 1468 y 1487 dificultan también el precisar, con certeza, durante cuanto tiempo este artista mantuvo una relación laboral con esta institución porque en 1462 no realizó ningún trabajo y en 1467 formó parte de los oficiales de la Fábrica cuando recibió los dos cahíces de trigo correspondientes a su salario anual. Los pagos conocidos señalan que, habitualmente, sus contratos con la catedral fueron por obra tanto en el sepulcro como en los primeros del programa de las portadas occidentales y un pago del mes de agosto de 1467 confirma que estaba casado y, evidentemente, vivía con su familia en Sevilla atendiendo desde su taller las demandas escultóricas de otros monasterios, templos y fieles de esta diócesis donde debió permanecer algún tiempo más ${ }^{21}$. Desconocemos quién o quiénes pudieron ser sus aprendices o sus ayudantes, y tampoco puede descartarse que, por su prestigio profesional, tallara en alabastro otros encargos y tumbas para lugares alejados de Sevilla (Fig. 3) ${ }^{22}$.

\section{EL PATROCINIO DEL CARDENAL CERVANTES EN LA CATEDRAL DE SEVILLA Y LAS CUENTAS DEL MA- YORDOMO ALONSO ENRÍQUEZ CON LORENZO MERCADER EN 1454}

Las noticias relativas a la implicación directa del cardenal Juan de Cervantes en las obras de la catedral son escasas pero significativas; atañen a los trabajos de cantería de la fachada occidental y a su intervención, a su voluntad, para gestionar la contratación del arquitecto y escultor valenciano Antoni Dal-

${ }^{21}$ ACSe, Sección IV Fábrica, Libro 9347(13) fol. 42r. Editado en F. REINA GIRÁLDEZ, Op.cit., p. 251.

${ }^{22}$ T. LAGUNA PAÚL, "The Virgin del Buen Fin...", pp. 49-50.

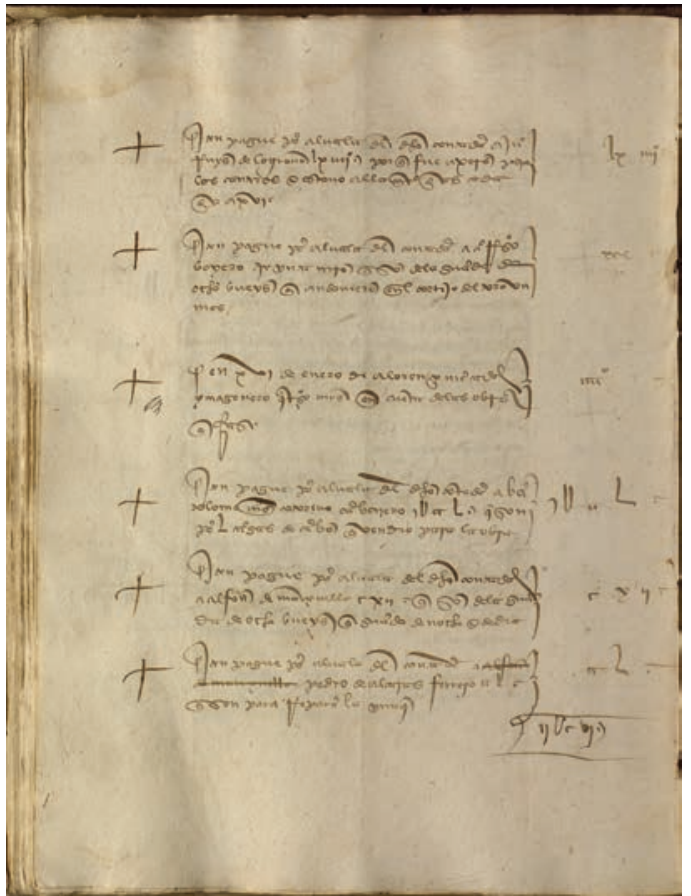

- Fig. 3. Libro de cuentas del mayordomo Alonso Enríquez del año 1454: asiento del pago realizado a Lorenzo Mercader del 16 de enero de 1454. Archivo de la catedral de Sevilla, Sección IV, Libro 9341(7), fol. 71v. (c) Cabildo Catedral de Sevilla.

mau y su taller. Sus relaciones personales, su habilidad en el ámbito de la diplomacia eclesiástica y civil, y su cargo como Administrador apostólico le situaron en una posición de influencia para cualquier decisión que adoptara el cabildo, donde colocó a buena parte de sus familiares y contó con prebendados de su absoluta confianza para supervisar aspectos relativos a la gestión económica de la Fábrica o de los ingresos de las bulas de indulgencia emitidas para la construcción del templo gótico.

La construcción de la catedral gótica de Sevilla impuso la necesidad de contar con experimentados arquitectos internacionales relacionados con las fábricas de los reinos de Aragón y Castilla como Isambart y Carlín, documentados en esta ciudad en 1433-1434 y 1435-1447 respectivamente. Antes de la marcha de este último y unos meses después de la llegada del cardenal Cervantes el estado de los trabajos y las necesidades de esta empresa gótica determinaron que el cabildo de 
la catedral solicitara la presencia en Sevilla de un maestro valenciano que, identificado con Antoni Dalmau, inspeccionó el estado de las obras y realizó muestras con sus ayudantes, desde finales del mes de enero hasta mayo de 1447. Dos años más tarde, este mismo maestro mayor y escultor de la catedral de Valencia recibió, en la capital del Turia, al canónigo hispalense Pedro Rodríguez, quien le llevó una carta del cardenal ofreciéndole el cargo de maestro mayor de la seo sevillana, y cuya propuesta declinó exigiendo unas condiciones excesivas para solventar, de manera políticamente correcta, su desinterés en dicha empresa ${ }^{23}$. Las primeras referencias de este valenciano (doc. 1435-1454) atañen a su formación escultórica en el taller de Pere Johan en la predela del retablo mayor de la seo zaragozana, auspiciado por el arzobispo Dalmau de Mur, hasta 1440 que volvió a Valencia para continuar su carrera profesional dirigiendo importantes obras civiles y religiosas como el trascoro de su catedral y la portada de la actual capilla del santo Cáliz, donde recientemente se han destacado analogías compositivas con la cantería de los accesos laterales de la fachada occidental sevillana $^{24}$. Estas referencias y el conocimiento de que Dalmau nunca cortó sus lazos profesionales con Zaragoza, donde posteriormen-

\footnotetext{
${ }^{23}$ A. JIMÉNEZ MARTÍN e I. PÉREZ PEÑARANDA, Cartografía de la Montaña Hueca, Sevilla, 1997, p. 47. M. GÓMEZ-FERRER LOZANO, “La cantería valenciana en la primera mitad del XV: El Maestro Antoni Dalmau y sus vinculaciones con el área mediterránea", Anuario del Departamento de Historia y Teoría del Arte, no 9-10, 19971998, pp. 101-103; actualizado en El maestro de la catedral de Valencia Antoni Dalmau (1435-1453), consultado el 18 de mayo de 2016. URL: http://www.academia. edu/11010998/. A. JIMÉNEZ MARTÍN, "Las fechas de las formas", en La catedral de Sevilla. Fundación y fábrica de la obra nueva, Sevilla, 2006, pp. 63-64; ÍDEM, "La catedral de Sevilla y el gótico mediterráneo", en B. ALONSO y F. VILLASEÑOR, Arquitectura tardogótica en la Corona de Castilla: trayectorias e intercambios", Santander, 2014, pp. 187-188 y 195-196. Maestre Isambart o Isanbart, Isambarte e Ysanbart; maestre Carlín o Carlín Gauter, Galter y Galtés de Ruán.

24 M. GÓMEZ-FERRER LOZANO, "La cantería valenciana...", pp. 92-94. J. IBÁÑEZ FERNÁNDEZ y D. DOMÍNGUEZ MONTERO, Op.cit., p. 184.
}

te trabajaron algunos escultores de su taller en su retablo mayor ${ }^{25}$, hacen que su figura adquiera cierto protagonismo en la fábrica hispalense ya que, pese a su negativa, pudo dar referencias de otros maestros canteros o de otros escultores internacionales dispuestos a trasladarse hasta el Guadalquivir donde sabían que tendrían un trabajo seguro y una clientela ávida de novedades artísticas. El aparejador de la catedral Juan Norman, o quizás este maestro valenciano, pudieron ser el puente a través del cual el cardenal Cervantes, alguno de sus familiares eclesiásticos o la catedral de Sevilla entablaran los contactos iniciales con Lorenzo Mercader para encargarle el sepulcro de este prelado ${ }^{26}$.

El cardenal, establecido definitivamente en Sevilla desde finales del verano de 1446, preparó su marcha de esta vida y solicitó una licencia testandi que firmó Nicolás $\mathrm{V}$ el 29 de octubre de 1448, pensó en el destino de sus bienes y en perpetuar su memoria descansando definitivamente en una capilla de la catedral de Sevilla y fundando un hospital donde dar continuidad a sus inquietudes sociales por los más débiles, ambas bajo la advocación de san Hermenegildo. La titulación está directamente relacionada con su interés por revitalizar el culto a este mártir, sus desvelos por encontrar sus reliquias, y supone un testimonio de los nacionalismos eclesiásticos iniciados entre los concilios de Constanza y Basilea cuando algunos prelados favorecieron la instauración de nuevos cultos o la promoción de otros ancestrales en sus diócesis ${ }^{27}$.

${ }^{25}$ M. C. LACARRA (coord.), El retablo mayor de San Salvador de Zaragoza, Zaragoza, 2000. Para la actualización documental de empresas artísticas en la Seo de Zaragoza antes y después de Dalmau de Mur: J. IBÁÑEZ FERNÁNDEZ y J. ANDRÉS CASABÓN, La catedral de Zaragoza de la Baja Edad Media al primer quinientos. Estudio documental y artístico, Zaragoza, 2016, pp. 70-105 y 110-126.

${ }^{26}$ F. REINA GIRÁLDEZ, Op.cit., p. 144. T. LAGUNA PAÚL, “The Virgen del Buen Fin...", p. 52.

27 J. PÉREZ-EMBID WAMBA, "La obra del P. Quintanadueñas en el contexto hagiográfico hispano", en A. QUINTANADUEÑAS, Santos de la ciudad de Sevilla 


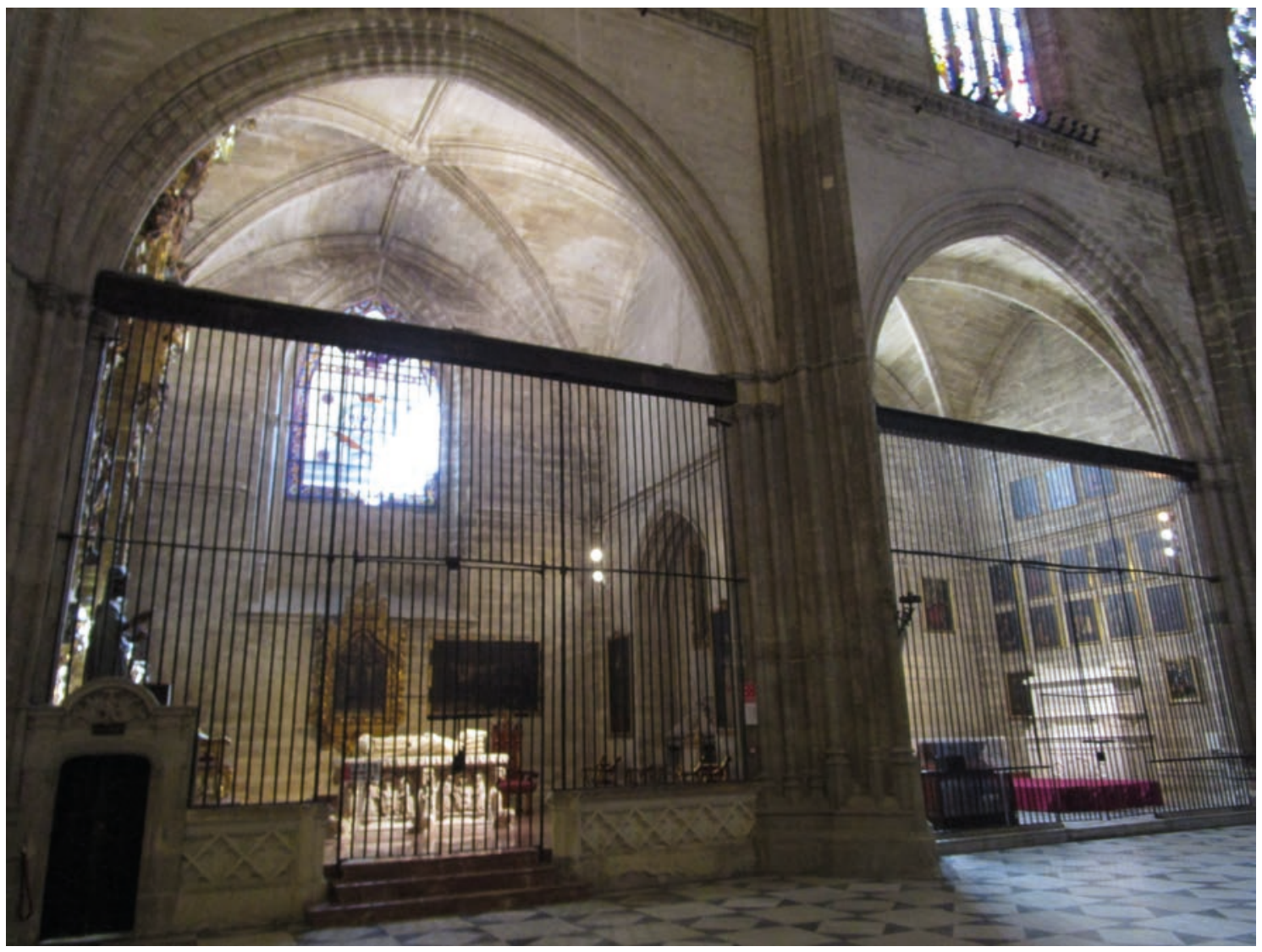

- Fig. 4. Catedral de Sevilla. Vista desde las naves de la catedral de la capilla de san Hermenegildo con el monumento funerario del cardenal Juan de Cervantes y del arco de comunicación con su antecapilla, cegado a finales del siglo XVIII al organizar la capilla de san José. Foto de la autora.

La fundación de la capilla de san Hermenegildo fue aprobada en 1451 y sus constituciones quedaron redactadas en octubre de 1453. Un mes más tarde el cardenal había elaborado personalmente su testamento y la distribución del reparto de sus bienes, que entregó por escrito al notario apostólico Pedro Martínez de Palma y firmó en presencia de varios testigos antes de ordenar cerrarlo y sellarlo el 16 de noviembre de 1453. En el testamento dispuso la fundación del hospital en unas casas de su propiedad en la collación de Santiago, dejó por su heredera a la "fabrica de la dicha nuestra iglesia de Seuilla", estableció diversas mandas y legados para sus familiares consanguíneos y eclesiásticos, sin olvidar los templos de las

y su arzobispado. Fiestas que su Santa Iglesia Metropolitana celebra (1637), Sevilla, 2006, p. 13-14. T. LAGUNA PAÚL "De la lineal al volumen...", pp. 141-143; ÍDEM, "Marco arquitectónico y retórica visual...", p. 43. diócesis de Ávila y Segovia con los que estuvo vinculado, las obras de caridad, las misas por su alma y algunas órdenes religiosas. También expuso su deseo de ser "enterrado en la dicha nuestra iglesia en la nuestra capilla de santo ermenegildo" y ordenó, expresamente, a sus "testamentarios et albaceas nos fagan fazer las obsequias e enterramiento según vieren que conuiene", concluir con sus bienes los trabajos pendientes en la capilla, disponer su ajuar litúrgico y hacer "un retablo y sepultura" ${ }^{28}$. Un día después del óbito,

${ }^{28} \mathrm{~J}$. ROMERO MALDONADO, “Testamento del cardenal Cervantes", Boletín de la Real Academia sevillana de Buenas Letras, $\mathrm{n}^{\circ}$ 41, 1924, pp. 121-131; p. 125 “[...] que de nuestros bienes se faga en nuestra capilla un retablo e sepultura e todas las otras cosas que a nuestros albaceas bien visto será que se faser deuan e que nuestros ornamentos pongan allí todos asy vestimentos como callices e cruzes e otras cosas e que la iglesia algunas fiestas solemnes si quisiere pueda usar de la capa e de 
el 26 de noviembre de 1453, el mismo notario procedió a su apertura y lectura en presencia de Alfonso Enríquez mayordomo de la Fábrica de la catedral y cuatro de sus albaceas: Fray Hernando de Torres prior de la cartuja de santa María de las Cuevas, el fraile jerónimo Pedro de Illescas, su pariente Gonzalo de Cervantes a quien había situado en el cargo de arcediano de Sevilla y su fiel secretario Juan González de Piñera que le acompañó, prácticamente, durante buena parte de su vida (Fig. 4).

Desde finales de noviembre de 1453 hasta junio de 1454, los encargos y tareas desarrollados por éstos y sus ayudantes fueron muchos, intensos e importantes y la documentación contable de la catedral evidencia encargos continuados para la puesta a punto de la capilla. Como se ha indicado, la catedral fue la heredera universal del legado del cardenal pero era obligado también realizar todas las disposiciones testamentarias, para lo cual fue necesario un inventario exhaustivo de todos sus bienes y fortuna con el fin de seleccionar aquellos pendientes de entrega a los herederos, los que permanecerían en la catedral y otros a enajenar con los que conseguirían los ingresos para canalizar, con dinero en metálico, algunas mandas testamentarias.

El testamento carece de un inventario pormenorizado $y$, en el caso de no existir, lo realizarían sus albaceas después de su lectura para conocer, sin dilación, el alcance real de todos sus bienes patrimoniales y proceder, cuanto antes, a su venta. El miércoles, viernes y sábado de la primera semana de 1454 enajenaron en la dependencia de la "traça", numerosos enseres, quedaron algunos pendientes y realizaron otra almoneda el 12 de marzo del mismo año ${ }^{29}$. Lamentablemente es imposible precisar si estas transacciones comenzaron a finales del año anterior porque no se conservan los libros de contabi-

la casulla de brocado ricas pero non sean muchas veces al año $[\ldots]^{\prime \prime}$.

${ }^{29}$ ACSe, Sección IV Fábrica, Libro 9341(7), fol. 13r., 13v. y 16v. lidad de 1453, no obstante el anuncio de esta venta y las visitas para conocer las pertenencias y obras de dicha almoneda despertarían gran interés durante las semanas previas a estas compraventas. Tampoco sabemos la relación y alcance de todos los bienes enajenados, porque su gestión quedaría anotada en un "libro de la fasienda del cardenal", adquirido por la Fábrica de la catedral junto con otros tres necesarios para escribir los asientos contables de aquel año y únicamente está localizado el libro de cuentas generales del mayordomo Alfonso Enríquez de $1454^{30}$. La información de este último nos aportó nuevas perspectivas de las obras que tenía contratadas Lorenzo Mercader en 1454, ya que supera una mera enumeración de las cuentas relativas a la escultura o bulto del mausoleo del cardenal Cervantes y de la Virgen de alabastro que instalaron en el altar de su capilla a finales del mes de diciembre de este año (Fig. 5).

A mediados del mes de enero de 1454 la catedral de Sevilla estaba inmersa en la gestión de las almonedas, había encargado la confección y adaptación de ornamentos para el ajuar de capilla del cardenal y conocía también al escultor contratado para tallar en alabastro la efigie del enterramiento del

${ }^{30}$ ACSe, Sección IV Fábrica, Libro 9341(7), fol. 14r.: "Íten, costaron quatro libros para remembrança desta facienda,/ e para el libro de las heredades e de los [ dos] e otras para/ la facienda del cardenal, çiento e treynta marauedís. CXXX", pago anotado entre los fechados el 19 y 22 de enero de 1454; fol. 1r: "Cuentas de los marauedís que Alonso Enríquez, [...] E con el alcançe que le fue fecho en su cuenta del/ anno que agora pasó de I (mil) CCCCLIII, e syn los marauedís de la herençia/ e facienda que fue e fincó del sennor don Juan de Çeruantes, Cardenal de Ostia, aministrador (sic) perpetuo de la eglesia e arçobispado de Seuilla, el qual fizo heredera a la fábrica de la dicha eglesia/ en su testamento, por quanto él reçibo de la dicha herençia está/ en otro libro aparte". Para los libros de contabilidad anual del siglo XV: I. MONTES ROMEROCAMACHO, "Los recursos financieros de la 'Obra' de la catedral de Sevilla durante el reinado de Enrique IV de Castilla (1454-1474). Los libros de fábrica", en A. JIMÉNEZ MARTÍN (coord.), La catedral después de Carlin. XVII Aula Hernán Ruiz, Sevilla octubre 2010, Sevilla, 2010, pp. 77-137. 


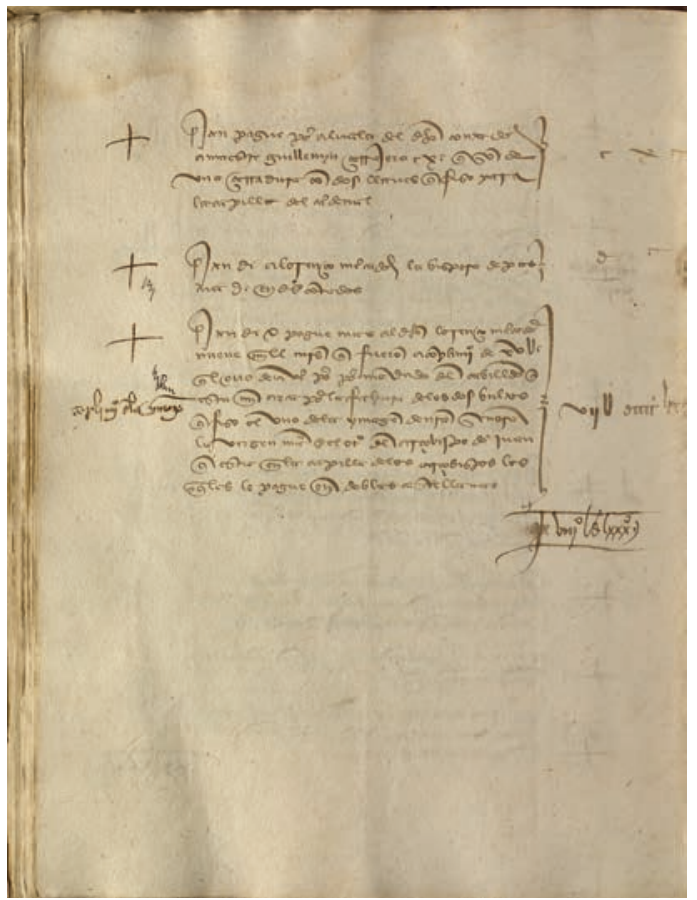

- Fig. 5. Libro de cuentas del mayordomo Alonso Enríquez del año 1454: registros de los últimos pagos efectuados a Lorenzo Mercader y del finiquito del contrato el 24 de diciembre de 1454. Archivo de la catedral de Sevilla, Sección IV, Libro 9341(7), fol. 72v. (C) Cabildo Catedral de Sevilla.

cardenal Juan de Cervantes. Establecidos los contactos necesarios, en una fecha todavía imprecisa, el maestro imaginero Lorenzo Mercader concertó con la catedral de Sevilla la realización de dos esculturas de alabastro para la capilla de san Hermenegildo, cuyos pagos en 1454 comprenden doce asientos contables con un importe total de 13230 maravedís, que leyó José Gestoso y publicó sumariamente Francisco Reina ${ }^{31}$. Esta cantidad es inferior a los 15000 señalados en el finiquito administrativo de su contrato, fechado la víspera del día de navidad del año 1454, cuando cobró los últimos 7470 maravedís pendientes que confirman, claramente, una

${ }^{31}$ ACSe, Sección IV Fábrica, Libro 9341(7), Obra nueva, fols. 55v., 60r., 60v., 63r., 63v., 64v., 70r., 71v., 72r. y 72v. José Gestoso nunca publicó estos pagos transcritos en 1887; véase Biblioteca Capitular y Colombina, Fondo Gestoso, Apuntes vol. V, "Extractos de las cuentas de la fabrica de la Yglesia mayor de Sevilla, por José Gestoso y Pérez, MDCCCLXXXVII", fol. 65v., 67r.-v., 68r.-v., 69v. y 70r. F. REINA GIRÁLDEZ, Op.cit., pp. 150-151. diferencia contable de 1770 respecto al importe del total acordado, y supone el 11,8\% a favor del escultor ${ }^{32}$. Una cifra significativa para omitirla en los registros del libro de cuentas generales de 1454, que podrían haberse registrado en el mencionado "libro de la herencia y hacienda del cardenal" o, sencillamente, desembolsado el año anterior, porque el 16 de enero de 1454 Lorenzo Mercader estaba en Sevilla y recibió 400 maravedís "en cuenta de las obras que face" ${ }^{\prime 3}$. Este registro fue anotado en la sección de la Obra nueva de este libro meses después de efectuarse el pago, entre otros sin fecha y dos efectuados al mismo escultor descargados el 26 de octubre y 9 de diciembre respectivamente. Evidentemente, el pago quedó desplazado de su posición natural debido a unos motivos que creemos relacionados con otros cambios constatados en este libro y explican, además, como en folios anteriores asentaron el pago del día 23 de marzo correspondiente a los 600 maravedís abonados "para la costa porque vino por su llamada desde Françia por vna carta suya para que labrase en la iglesia", publicado por Francisco Reina (Fig. 6) ${ }^{34}$.

Administrativamente fue un año complejo para Alfonso Enríquez, mayordomo de la catedral entre 1452 y 1454, no sólo por el implemento que tuvieron los gastos cons-

${ }^{32}$ ACSe, Sección IV Fábrica, Libro 9341(7), Obra nueva, fol. 72v.: "Conplimiento de la ymagen./ Íten, di e pagué más al dicho Lorenço Mercader/ nueue mill marauedís que fueron a conplimiento de XV(mill) (marauedís)/ quél ouo de aver por por (sic) mandado del cabilldo, que/ está mi arca, por la fechura de los dos bultos/ que fizo, el vno de la ymagen de Nuestra Sennora/ la Virgen María, e el otro del Arçobispo don Juan/ que está en la capilla de los arçobispos, los/ quales le pagué en doblas castellanas. VII(mill)DCCCCLXX (marauedís). (Al margen derecho)". Editado parcialmente en J. GESTOSO y PÉREZ, Op.cit., vol. II, p. 520; F. REINA GIRÁLDEZ, Op.cit., pp. 148 y 150 nota 32.

33 ACSe, Sección IV Fábrica, Libro 9341(7), Obra nueva, fol. 71v.: "En XVI de enero di a Lorenço Mercader, ymaginero, quatroçientos marauedis en cuenta de las obras que face", editado en F. REINA GIRÁLDEZ, Op.cit., p. 149.

${ }^{34}$ ACSe, Sección IV Fábrica, Libro 9341(7), fol. 55v. Editado en F. REINA GIRÁLDEZ, Op.cit., p. 144. 


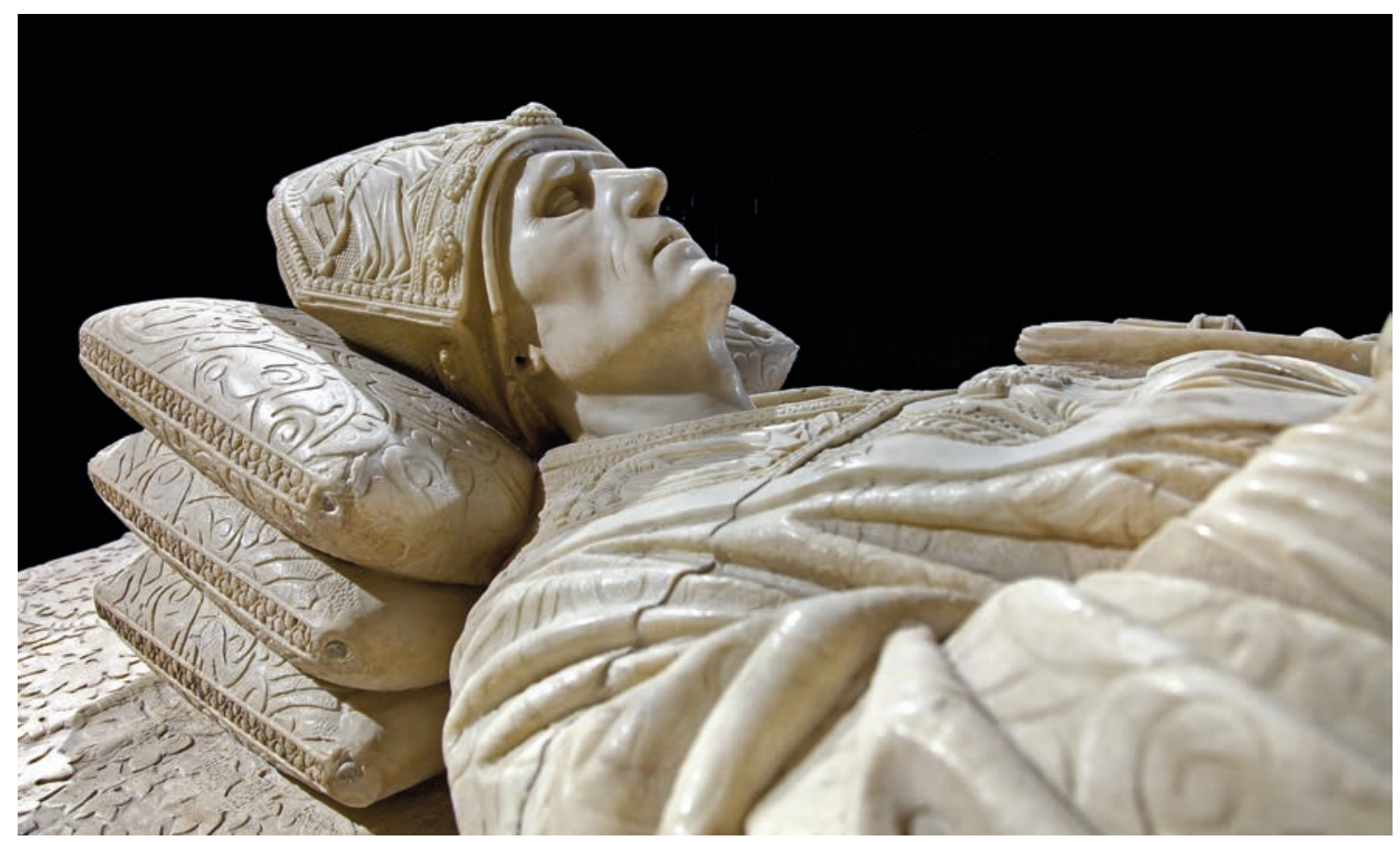

- Fig. 6. Lorenzo Mercader / Lorenzo Mercadante de Bretaña, pormenor de la parte superior del cuerpo y costado derecho de la escultura del cardenal Juan de Cervantes. 1454. Catedral de Sevilla, capilla de san Hermenegildo. Foto de la autora.

tructivos de la Obra nueva de la Fábrica sino porque, al hacerse cargo del sustancioso legado del cardenal Cervantes, tuvo que discutirlo con los intereses de la Mesa arzobispal y litigar en el pleito que Don Alfonso de Fonseca, el nuevo arzobispo, disputó con la Fábrica por la herencia libraria de su antecesor. Estas circunstancias y el aumento de trabajo sobrecargaron las tareas habituales del personal de la mayordomía, que fue gratificado con 4000 maravedís a finales de diciembre $^{35}$. En 1454 las inversiones y pagos ascendieron a 987539 maravedís y de esta cantidad el 86\% (569 556) correspondió a las obras de construcción; la Fábrica ingresó 820070 y en el balance anual hubo un vacío contable de 167468 cuya diferencia cubrió este mayordomo, poco a poco, en los años siguientes anotándosele en el libro de la "herencia y facienda del cardenal". El alcance

${ }^{35}$ ACSe, Sección IV Fábrica, libro 9341(7), fol. 75v. Citado en I. MONTES ROMERO-CAMACHO, Op.cit., p. 81. Para pleito y concordia: C. ÁLVAREZ MÁRQUEZ, Manuscritos localizados de Pedro Gómez Barroso y Juan de Cervantes, arzobispos de Sevilla, Alcalá de Henares, 1999, pp. 80-82. de las cuentas, lamentablemente, era una circunstancia que ocurría en algunas ocasiones a comienzos del año siguiente cuando cerraban administrativamente los gastos generales del anterior ya que, fundamentalmente, el mayordomo se limitaba a dar curso a los libramientos y mandamientos que le comunicaban los contadores; no controlaba el dinero que servía para abonar los gastos de la Obra vieja, ni de los materiales de la Obra nueva, ni de las nóminas de los canteros y peones que trabajaban en la catedral ${ }^{36}$.

El aumento del trabajo y otras circunstancias motivaron cambios en los criterios de copia de los registros contables de la Obra nueva y de los libramientos del contador Gonzalo Yannes de Farias efectuados durante el primer trimestre de 1454, cuyas partidas están tachadas en los folios 7r. al 12r. y asentadas también a partir del folio 53r. del

${ }^{36}$ J. A. OLLERO PINA, "Los mayordomos de la fábrica de la catedral en el siglo XV (1411-1516)", en A. JIMÉNEZ (coord.), La catedral entre 1434 y 1517: historia y conservación. XX edición del Aula Hernán Ruiz, Sevilla, 2013, pp. 153-154. 
mismo libro ${ }^{37}$. Al comenzar el año y escribir los gastos de la Obra nueva en las primeras hojas alteraron la organización habitual establecida para los libros de gastos generales $y$, por este motivo, interrumpieron la anotación de sus pagos a finales del mes de marzo, los gastos de la Obra vieja los comenzaron en la primera hoja del segundo cuadernillo y les reservaron cuarenta hojas para asentarlos, y los pagos de la Obra nueva están escritos a partir de las seis últimas hojas del tercer cuadernillo $^{38}$. Igualmente al apuntar de nuevo los descargos de los albalás, de los recibos y de las nóminas semanales de la Obra nueva alteraron las normas seguidas hasta finales de marzo en los primeros folios y, en vez de anotarlos al final de cada mes natural, están reagrupados tres veces detrás de numerosos pagos y albalás, que suelen omitir la fecha del descargo salvo en los relativos a los canteros de Jerez, los de las almonedas de bienes y los del imaginero bretón ${ }^{39}$. En la copia de los registros de la Obra vieja y Obra nueva constaté algún error en el asiento respecto a la cifra escrita al margen cuya suma siempre es correcta $y$, ante todo, cierto desorden en la secuencia cronológica de las anotaciones

37 ACSe, Sección IV Fábrica, Libro 9341(7), fol. 7r.: "Estos son los marauedís que yo, el dicho Alonso Enríquez, raçionero e mayordomo/ de la fábrica de la iglesia de Seuilla, he despendido e pagado [...]. Estas seys fojas/ siguientes se testaron/ porque las partidas/ en ellas contenidos/ están sentados ade-/lante en este libro/ en diuersos logares".

38 Los libros de cuentas generales comprenden, habitualmente, tres o cuatro cuadernos de 12 hojas de papel dobladas; la copia de los gastos de la Obra vieja es inmediata a la de ingresos anuales y en las hojas finales del segundo o tercer cuadernillo comienzan los de la Obra nueva. Ibídem, Libro 9341(7): C1-7º fols. Or.v., contraguarda a 12r., portada, título, ingresos y Obra nueva (tachados); C2-12 fols. 13r.-36v. Obra vieja; C3$11^{\mathrm{o}}$ fols. 37r. $-47 \mathrm{r}$. Obra vieja, fols. $47 \mathrm{v} .-52 \mathrm{v}$. en blanco y fols. 53r.-58v. Obra nueva; C4-12 ${ }^{\circ}$ fols. 59r.-81r. Obra nueva, Oficiales, cuenta mayor, 81v.-82r. en blanco y 82-v. contraguarda pegada a la encuadernación de pergamino.

39 Ibídem, Libro 9341(7): fol. 54v.-55r. nóminas semanas del 1-1-1454 al 9-2-1454, fols. 65r.-70v. del 112-1454 al 29-10-1454 y fols. 73v.-75r. del 21-10-1454 al 4-1-1455. contables como, por ejemplo, en "un almud de yeso" de características especiales que fue necesario adquirir para "reparar" el bulto del cardenal realizado por Lorenzo Merca$\operatorname{der}^{40}$.

Este cambio de criterio en la organización del libro general de cuentas de 1454 y la omisión de las fechas de los albalás puede deberse, también, a la existencia de otro libro de contabilidad adquirido separadamente de los cuatro antes citados: el libro de los albalás de Diego Marmolejo donde podrían contrastar toda la información de los pagos realizados por los contadores con mayor precisión ${ }^{41}$. Las fechas de los descargos de las almonedas y abonos al escultor se consignarían por su trascendencia, por la intervención de algunos intermediarios que efectuaron ciertos pagos o por el control ejercido por los albaceas y ésto explicaría porqué el recibo o nota del 16 de enero de 1454 pudo entregarse con cierto retraso en la mayordomía y quedara, guardado o traspapelado, pendiente de anotación durante cierto tiempo ${ }^{42}$. Finalmente, al desconocer la fecha exacta de los primeros contactos de Lorenzo Mercader con la catedral de Sevilla tampoco puede descartarse algún pago efectuado por la Fábrica de esta seo o directamente por el secretario del cardenal, Juan González de

${ }^{40}$ Ibídem, Libro 9341(7), Obra vieja, fol. 40v., pago precedido por dos efectuados el día 2 de noviembre $\mathrm{y}$ estos por otros abonados a finales del mismo mes. Citado en J. GESTOSO y PEREZ, Op.cit., vol. II, p. 520; F. REINA GIRÁLDEZ, Op.cit., p. 148.

${ }^{41}$ ACSe, Sección IV Fábrica, Libro 9341(7), fol. 43v., "Costó vn libro para escriuir las alualaes de/ Diego Marmolejo, quince maravedís".

42 Ibídem, Libro 9341(7), fol. 60r.: "Íten, pagué por mandado del mayordomo a Lo-/renço Mercader, ymagenero, en quatro de jullio,/ trecientos marauedís, los quales di por él a Ferrando/ de Seuilla, tempero. $\mathrm{CCC}^{\prime}$; fol. 70r., "En veynte e seys de otubre, pagué/ a Lorenço Mercader, ymagenero, para en cuenta/ de la ymajen que face, CCCL (marauedís), los quales le dio mio/ sennor, e gelos dio a él Ferrand Gastón. Íten/ le di yo a él CL (marauedís), que son todos seysçientos marauedís. CCCL". Citado en F. REINA GIRÁLDEZ, Op.cit., p. 151, notas 34 y 35. 
Piñera, en fechas cercanas o inmediatas al óbito de éste.

Esta presencia de Lorenzo Mercader en Sevilla a principios del mes de enero queda, también, confirmada por la diferencia contable de la suma de todos los pagos efectuados en 1454 donde ya señalé existe un importe del 11,8 \% a favor del escultor que debió recibir en una fecha indeterminada de 1453, relacionada con el encargo y contratación de las dos esculturas. La ausencia de noticias relativas a la vida o profesión del escultor desde que liquidó su compromiso en Zaragoza con Fontaner de Usesques el 29 de mayo de 1448 impide establecer el momento exacto en que se desplazó a Sevilla o contactó con el cardenal, con sus albaceas o con su heredera la Fábrica de la catedral de Sevilla. Tampoco puede confirmarse su presencia en esta ciudad andaluza durante las semanas previas al óbito del cardenal que presupondrían un conocimiento directo de él, la realización de algún apunte o retrato a lápiz, incluso de su mascarilla funeraria para reflejar fehacientemente sus rasgos en la escultura. La noticia e importancia del encargo pudo motivar que llegara con cierta premura, llevara a cabo las gestiones necesarias o los acuerdos oportunos con la catedral y marchara semanas después de percibir los señalados 400 maravedís el día 16 de enero para organizar sus asuntos personales o profesionales antes de instalarse durante una larga temporada en esta ciudad y cobrar el 23 de marzo los citados 600 maravedís por los gastos de su viaje y por "su llamada desde Françia por una carta suya para que labrase en la iglesia" (Fig. 6) ${ }^{43}$.

La catedral de Sevilla abonaba las costas de viajes cuando convocaba a especialistas para recabar su opinión respecto a problemas técnicos de envergadura o bien cuando buscaba artistas foráneos que contrataba para llevar a cabo la dirección de obras o encargos artísticos, cuya duración se estimaba superior a un año, como se de-

${ }^{43}$ ACSe, Sección IV Fábrica, Libro 9341(7), fol. 55v. Editado en F. REINA GIRÁLDEZ, Op.cit., p. 144. duce, por ejemplo, en el asiento contable de la contratación de maestre Isambart el 7 de julio de $1434^{44}$. Esta costumbre también fue habitual para los servidores de la monarquía cuando se incorporaban a los trabajos del cabildo municipal de Sevilla. El pago de estos gastos por desplazamiento solía ser inmediato a su llegada o a la emisión de ciertos peritajes caso de los abonos efectuados a Juan de Álava, Juan de Badajoz y Juan Gil de Hontañón al convocarlos en agosto de 1513 para debatir los problemas de la capilla mayor y cierre del crucero catedralicio. En otra ocasión, en noviembre de 1517, cuando llamaron a Miguel Perrin para contratar las esculturas del segundo cimborrio le pagaron 20 ducados de oro para "ropa e para su gasto", y después varias cantidades a cuenta aunque durante cinco meses no pudo realizar su trabajo porque el cabildo incumplió facilitarle el taller prometido, lo que motivó quejas reiteradas del escultor ${ }^{45}$. Desconocemos si ocurrió algo semejante en el descargo contable del viaje de Mercadante, ya que el día de su pago, el 23 de marzo de 1454, no implica necesariamente una primera estancia o contacto con la catedral de Sevilla y puede obedecer a otras circunstancias como que el cabildo deseara evitar una demora excesiva en el regreso del escultor y acordaran abonar esta cifra a su vuelta; la mención "desde Françia" quizás haga referencia a sus orígenes en vez de al territorio o reino desde el que se desplazó expresamente en aquella ocasión. Tampoco debemos descartar un viaje motivado por la selección, adquisición y transporte del alabastro omitido sistemáticamente en todos los libros de la contabilidad conservada, bien porque su coste estuviera

${ }^{44}$ Ibídem, Libro 9336 (2B), fol. 8r.: "Este día se fizo el contracto entre el cabildo e maestre Ysambret en razón de la obra nueua de la eglesia, e mandó el cabildo que le diese para ayuda de la cos-/ta para el camino e por los días que aquí estado CL (maravedis)". Editado en J. GESTOSO y PÉREZ, Op.cit., vol. II, p. 33, nota 1.

${ }^{45}$ T. LAGUNA PAÚL, "Llegada y primeras obras de Miguel Perrin en la catedral de Sevilla: el programa escultórico de la reconstrucción del cimborrio de Juan Gil de Hontañón", Laboratorio de Arte, nº 24, 2012, pp. 142-145. 
incluido en la formalización del contrato o en los acuerdos con el escultor, fuera comprado anteriormente o anotado directamente en el libro de la herencia del cardenal. Este aspecto constituye siempre un capítulo importante y perfectamente especificado en las contrataciones de escultura, tanto para controlar la calidad de la piedra, mármol o alabastro como por su importe, que podía alcanzar entre una cuarta parte y un tercio del coste total en un monumento funerario ${ }^{46}$.

El contrato o el acuerdo con Lorenzo Mercader, como en otras ocasiones, pudo incluir los costes del alabastro y todos los trabajos del escultor: la selección en la cantera, el material y su transporte hasta Sevilla, el trabajo escultórico en el taller, el salario quizás de algún ayudante y la instalación en la catedral. En la redacción del documento constarían las características de las dos obras, el tiempo de ejecución, alguna cláusula de penalización para evitar incumplimientos y, posiblemente, una estimación del coste de cada escultura de alabastro, ya que el finiquito de 24 de diciembre de 1454 señala el pagó de 9000 maravedís "que fueron a conplimento" de los 15000 del contrato de la imagen de Nuestra Señora y de la escultura del arzobispo; esta cantidad equivale al 60\% contratado y debería corresponder al precio unitario del bulto del cardenal concluido en aquella fecha. El documento fijaría los plazos de entrega y forma de pago, que por los descargos parece establecer dos mitades casi equitativas para el importe contratado. La primera comprendería la cantidad entregada al contratar y los descargos realizados a cuenta, ya que según la contabilidad corresponden al 34\% de los pagos de 1454 (5100 maravedís), al 4\% del importe del viaje (600 maravedís) y el 11,8\% restante a todos los

46 Véase por ejemplo los contratos de los monumentos funerarios del sepulcro de Juan II en la cartuja de Miraflores (1489), o el de Álvaro de Luna y Juana Pimentel en la catedral de Toledo (1489), J. M. de AZCÁRATE, Colección de documentos para la Historia del Arte en España 2. Datos histórico-artísticos de fines del siglo XV y principios del XVI, Zaragoza, 1982, pp. 54-55 y 242244 efectuados en 1453 (1770 maravedís) ${ }^{47}$. El importe de la segunda mitad contratada quedó aplazado a la finalización e instalación de las dos esculturas (15 000 maravedís), cuyo finiquito supone el 50,2\% (7470 maravedís) ${ }^{48}$. Según estos asientos contables el ritmo de los trabajos fue simultáneo a la terminación de las obras pendientes en la capilla, la escultura de la Virgen se entregaría al finalizar el verano y la del cardenal en diciembre.

El espacio destinado por el cabildo y el cardenal Juan de Cervantes para su capilla funeraria obedece a las necesidades de una fundación acorde con la trayectoria vital de su promotor y fundador, a su relevancia internacional e implicaciones con la iglesia de Sevilla. La capilla de san Hermenegildo es la única de todo este templo que ocupa dos contiguas, cerradas por rejas y separadas por un arco de comunicación ojival decorado con un gablete y un crochet abierto, seguramente al gestionar su fundación en 1451, que se conserva parcialmente detrás del ático del retablo de san José; un espacio privilegiado digno para un príncipe de la Iglesia que prolongaría su recuerdo, su memoria hasta el final de los días. La primera capilla careció de acceso directo desde el templo hasta finales del siglo XVIII, es propiamente el espacio funerario con el mausoleo en el centro orientado hacia el altar del mártir visigodo, situado en el muro común con la capilla de la Antigua que fue alterado al construir el pasillo de comunicación con la sacristía de ésta en $1502-1510^{49}$. La segunda, que comunicaba

${ }^{47}$ ACSe, Sección IV Fábrica, Libro 9341(7), fol. 56r., 204-1454, 200 maravedís; fol. 60r., 4-7-1457, 300 maravedís; fol. 60v., 20-7-1454, 200 maravedís; fol. 63r., 7-8-1454, 500 maravedís; fol. 63v., 9-9-1454, 500 maravedís; fol. $64 \mathrm{v} .$, sin fecha, 0 maravedís; fol. 70r., 26-10-1454, 500 maravedís; fol. 71v., 16-1-1454, 400 maravedís: fol. 72r., 9-12-1454, 500 maravedís; fol. 72r., 13-12-1454, 1000 maravedís; fol. 72v., 24-12-1454, 500 maravedís.

${ }^{48}$ Ibídem, fol. 55v., viaje 23-3-1454, 600 maravedís; fol, 72v., finiquito 24-12-1454, 7470 maravedís.

${ }^{49}$ A. JIMÉNEZ MARTÍN, "Rarezas de la capilla de la Antigua", en La piedra postrera. $V$ centenario de la conclusión de la catedral de Sevilla, (2) comunicaciones, Sevilla, 2007, pp. 406-408; ÍDEM, Anatomía de la catedral 
además con la casa del cardenal, era propiamente una antecapilla donde únicamente recibieron sepultura algunos de sus familiares eclesiásticos o del personal directamente vinculado con él: Andrés Fernández de Cuéllar, Alonso González de Orvaneja y Luis del Castillo $^{50}$. En 1451 la construcción de ambos espacios estaría avanzada y el cardenal la incentivaría para tenerlos acabados antes de terminar las constituciones de la capilla en octubre de 1453; su avanzada edad y su delicado estado de salud le impidieron verla concluida y, en su testamento, encomendó terminar las obras pendientes y realizar un retablo y su sepultura cuyas características o preferencias al respecto pudo haber transmitido a sus familiares de confianza, especialmente a los que nombró sus albaceas y a algunos miembros del cabildo de la catedral, su heredera. A su muerte el sepulcro estaba todavía pendiente y, como ya apuntó el profesor Yarza, sería alguien de su confianza quien buscara a un artista singular ${ }^{51}$.

En noviembre de 1453, cuando falleció, tenían incompletos y pendientes algunos aspectos suntuarios, decorativos y escultóricos que documentalmente abonaron en su mayoría durante el transcurso del primer semestre del año siguiente y disminuyeron drásticamente a partir del mes de junio, cuando ya habrían cubierto la mesa del altar con los seiscientos azulejos adquiridos a Gonzalo Yannes de Farias el 22 de febrero de $1454^{52}$. Esta obra de albañilería y otras tareas compitieron a los peones de la catedral,

de Sevilla, Sevilla, 2013, pp. 192, 289-209 y fig. 111.

50 ACSe, Sección V.1.2, Libro de los aniversarios solemnes y simples assi de Reyes [...], asientos no 278-281. Editado en J. PÉREZ-EMBID WAMBA, Culto funerario y registro cronológico de la catedral de Sevilla (siglos XIII-XV), Madrid, 2015, pp. 313-316.

51 J. YARZA LUACES, "“Hombres de poder, gentes del libro, "Viri Litterati" y encargos artísticos", en catálogo exposición El marqués de Santillana (13981458), los albores de la España Moderna. El humanista, Hondarribia, 2009, pp. 16-17.

${ }^{52}$ ACSe, Sección IV Fábrica, Libro 9341(7), fol. 10r. y 54r. J. GESTOSO y PÉREZ, Op.cit., vol. II, p. 520, editado en fol. $54 \mathrm{r}$. remunerados en sus nóminas semanales sin especificar lo realizado. Estos mismos operarios serían los encargados de trasladar al altar de esta capilla una imagen de la Virgen, que la catedral adquirió a principios del verano al canónigo beneficiario Pero Estevan por 490 maravedís y presidió el altar durante algunos meses, a la espera de la encargada a Mercadante de Bretaña ${ }^{53}$. Desde mediados de aquel estío se confirma un culto continuado en este ámbito por parte del sacristán y de los beneficiarios de las capellanías dotadas $^{54}$. La nueva escultura mariana, que Diego Angulo identificó con la Virgen del Madroño, estaba concluida a finales del ve-

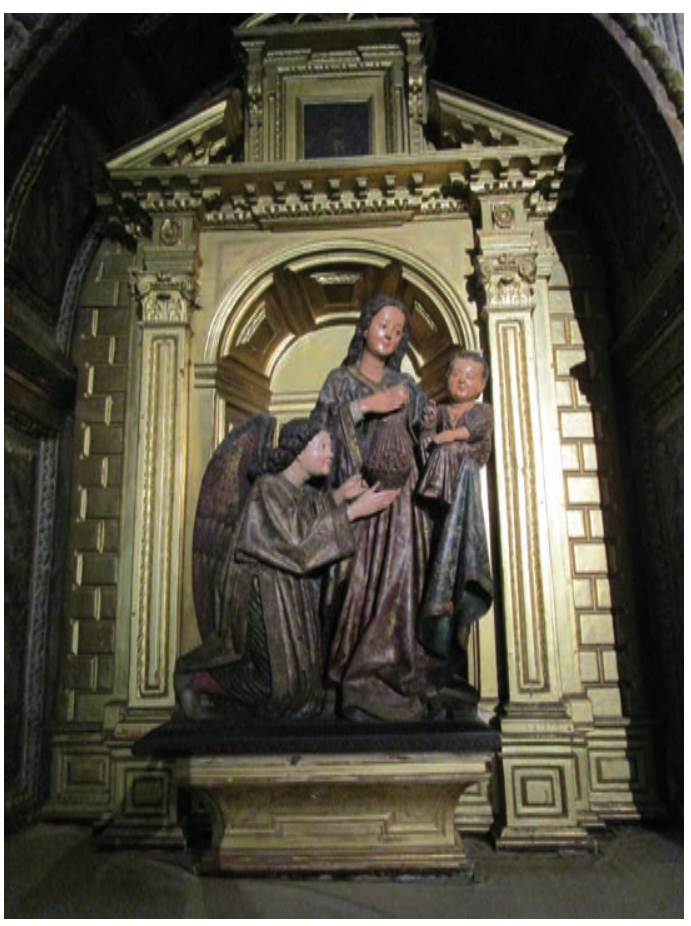

- Fig. 7. Virgen del Madroño, identificada por Diego Angulo con la imagen mariana esculpida por Lorenzo Mercader en 1454. Catedral de Sevilla, altar de la Virgen del Madroño. Foto de la autora.

53 ACSe, Sección IV Fábrica, Libro 9341(7), Obra vieja, fol. 30r.: "Pero Esteuan, canónigo. Iten, di a Pero Esteuan, canónigo, que le mandaron dar en/ remuneraçión de la Santísima María que agora etá en/ la capilla del cardenal, que la tomaron de su casa, CCCCXIX (marauedís)".

\footnotetext{
${ }^{54}$ Ibídem, Libro 9341(7), fol. 79v.-80r.
} 
rano aunque, al parecer, su instalación definitiva no fue inmediata porque encargaron al maestro mayor de carpintería, Bartolomé Sánchez, la realización de dos coronas doradas, terminadas a finales de septiembre, y después un tabernáculo lígneo que decoró el pintor Alonso López en la primera quincena de diciembre y colocarían en el altar de dicha capilla, coincidiendo con la finalización y entrega de la escultura funeraria del cardenal (Fig. 7) $)^{55}$.

Según esta documentación contable, el bulto del cardenal fue la segunda escultura que entregó Lorenzo Mercader en 1454 ya que, a finales de noviembre, la mayordomía de la catedral abonó 12 maravedís para una partida de yeso de características especiales, que necesitó para terminarla e instalarla en la catedral, sin tener que esperar la realización completa del resto del monumento con su paño, los relieves de la cista con sus tabernáculos y esculturas y el zócalo del basamento con los seis leones ${ }^{56}$. Los vacíos documentales del archivo impiden precisar durante cuantos meses y en qué año efectuaron el montaje de todas estas partes y de sus distintas piezas pues, únicamente, hay constancia de que en febrero de 1458 le abonaron 2000 maravedís por las "estorias" del monumento, los relieves situados en los frentes y laterales de la cista con ángeles portando las armas del prelado que exaltan su linaje $\mathrm{y}$, simbólicamente, elevan su alma al cielo ${ }^{57}$.

55 Ibídem, Libro 9341(7), fol. 34r., 38r. y 42r. Editado en F. REINA GIRÁLDEZ, Op.cit., p. 150; fol. 34r., editado en J. GESTOSO y PÉREZ, Ensayo de un diccionario de los artífices que florecieron en Sevilla desde el siglo XIII al XVIII inclusive, Sevilla, 1899, vol. I, p. 69. I. RÍOS COLLANTES DE TERÁN, "Bartolomé Sánchez: maestro mayor de carpintería de la obra de Santa María (i-1464)", en A. JIMÉNEZ MARTÍN (coord.), La catedral después de Carlin. XVII Aula Hernán Ruiz, Sevilla octubre 2010, Sevilla, 2010, pp. 19-20.

${ }^{56}$ ACSe, Sección IV Fábrica, Libro 9341(7), Obra vieja, fol. 41r. Citado en J. GESTOSO y PÉREZ, Sevilla monumental..., vol. II, p. 520, F. REINA GIRÁLDEZ, Op.cit., p. 148

${ }^{57}$ ACSe, Sección IV Fábrica, Libro 9342 (8), fol. 12v. Citado en J. GESTOSO y PÉREZ, Sevilla monumental..., vol. II, p. 520. F. REINA GIRÁLDEZ, Op.cit., p. 148.
La contratación inicial y entregas de la imagen mariana y del bulto del cardenal, aparte de suponer una validación de las expectativas que la catedral habría depositado en Lorenzo Mercader, daría paso a una segunda etapa en la ejecución del monumento que debió estar prevista o acordada desde el primer momento. El cardenal fue amortajado con una casulla blanca del Sagrario de la catedral y, concluido el funeral, trasladado a una sepultura provisional, un pudridero o enterramiento temporal ${ }^{58}$. Años más tarde descarnaron sus huesos y los depositaron en el interior de una urna de madera pintada y personalizada con su escudo que fue colocada en el interior del núcleo de mortero y ladrillo construido sobre el plinto de alabastro y descubierta en el año 2003, al restaurar el sepulcro (Figs. 8 y 9) ${ }^{59}$. Los restos del hueco ocupado por esta urna de 46 × 87,5 x 31,5 $\mathrm{cm}$. aclaran otros aspectos desconocidos de la inhumación del cardenal y del tiempo empleado en la realización de la cista funeraria.

El primer enterramiento o sepultura del cuerpo del cardenal pudo estar localizado en el centro de esta misma capilla o en otro ámbito catedralicio en el interior de un depósito provisional, en el suelo o bien construido con muros de fábrica que destacarían visualmente con su capelo cardenalicio, su galero escarlata colocado encima o colgado de la bóveda siguiendo las remotas costumbres que todavía mantiene la catedral de Tole$\mathrm{do}^{60}$. A finales de 1454 o comienzos de 1455 ,

58 ACSe, Sección IV Fábrica, Libro 9341(7), Obra vieja, fol. 44r., editado parcialmente en J. GESTOSO y PÉREZ, Sevilla monumental..., Vol. II, p. 410; folio 45r., "Di a las amigas por la fechura de la vestimenta blanca que ficieron para la capilla de Sant Clemeynte, la qual se fizo en logar de otra que tomaron que lleuó vestido el sennor cardenal, çinquenta maravedís".

${ }^{59}$ A. JIMÉNEZ SANCHO y A. JIMÉNEZ MARTÍN, "La restauración del sepulcro del cardenal Cervantes de la catedral de Sevilla", en En el umbral de la memoria. Actas de las XIII jornadas internacionales de intervención en el patrimonio histórico-artístico, (COAR, Logroño, 3-6 noviembre 2055), Logroño, 2005, pp. 308 y 311.

${ }^{60}$ ACSe, Sección IV Fábrica, Libro 9341(7), Obra vieja, fol. 45r.: "Íten, le di por reparar vn sonbrero del carde-/ 


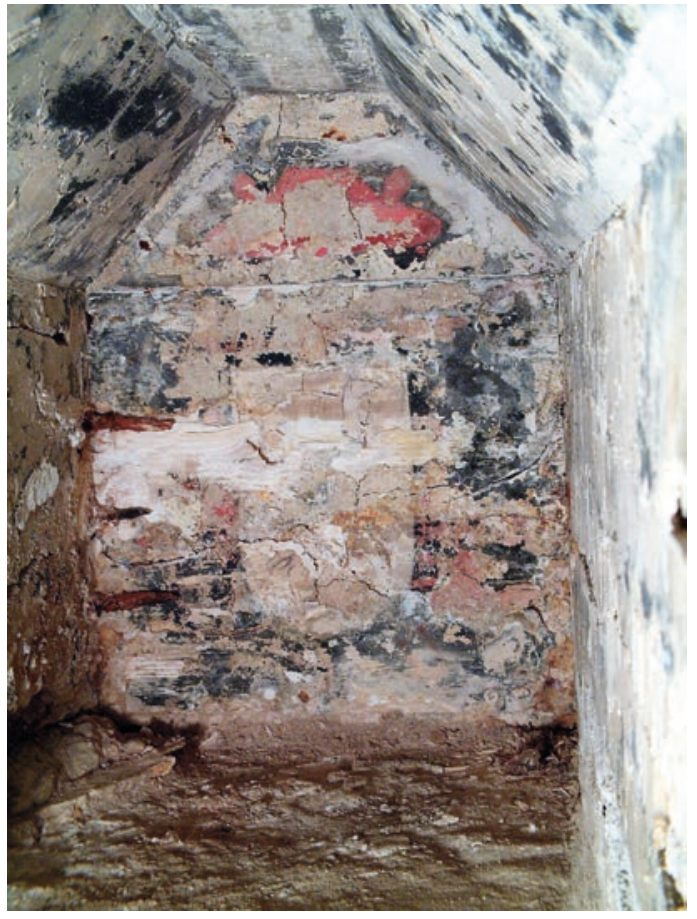

- Fig. 8. Vista interior o huella de la urna de los restos del cardenal Juan de Cervantes descubierta en el núcleo interior de su monumento funerario. Catedral de Sevilla, capilla de san Hermenegildo. Foto de Álvaro Jiménez Sancho.

terminada la escultura del cardenal, tallada en cuatro bloques con un peso de $528 \mathrm{Kgr}$, pudieron colocarla sobre esta sepultura temporal apoyada en unos tableros, ocultos por algún paño rico, que a su vez descargaran sobre los muros de fábrica que rodearan el depósito provisional del cadáver. Dicha instalación reproduciría parcialmente el modelo del monumento aprobado, que sigue las directrices de otros mausoleos que evocan el lecho mortuorio con el cadáver dispuesto para su velatorio en la capilla ardiente; una iconografía representada desde finales del siglo XII en los monumentos funerarios de los Plantagenet en Fontenvrault y que tuvo amplio desarrollo en tumbas eclesiásticas y civiles del período gótico durante los siglos XIV y XV ${ }^{61}$. En los reinos de la península Ibé-

nal e enforrallo, veynte maravedís".

${ }^{61}$ Para una bibliografía sobre éstos: A. ADAMS y J. BARKER, Revisiting the monument. Fifty years since Panofsky's Tomb Sculpture, London, 2016; N. BOCK, I, FOLETTI y M. TOMASI, L'érêque, l'image et la mort.

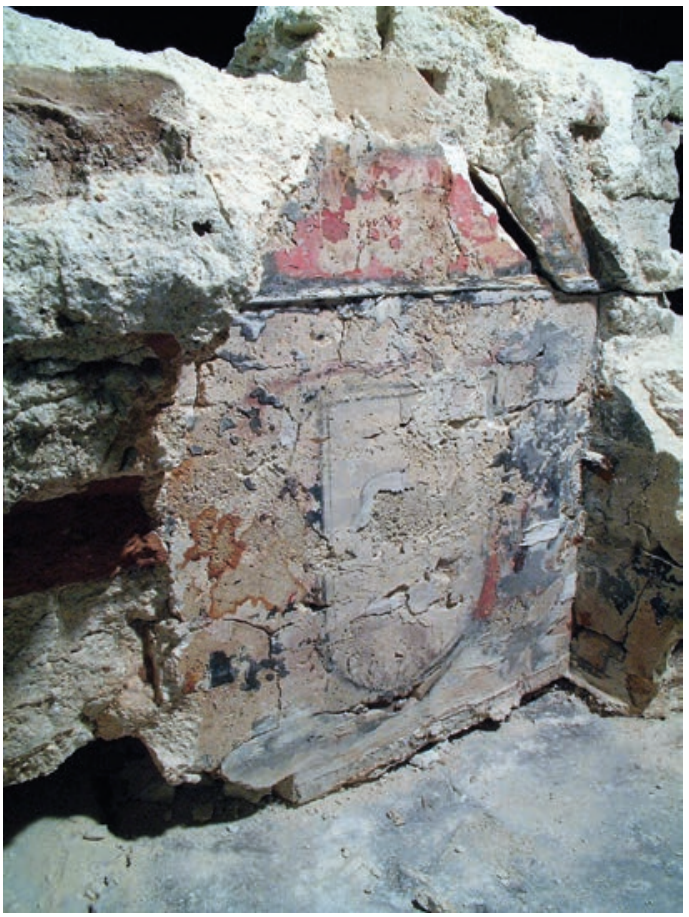

- Fig. 9. Escudo pintado en el otro frente de la urna de madera de los restos óseos del cardenal Juan de Cervantes. Foto de la autora.

rica existen testimonios pictóricos y escultóricos desde mediados del siglo XV cuyo análisis, en relación con el mausoleo de Juan de Cervantes, supera los límites requeridos en esta publicación y desarrollaré, próximamente, para tratar su técnica escultórica y policromía, su diseño e iconografía funeraria en el contexto español e internacional ${ }^{62}$.

Esta primera instalación del sepulcro del cardenal permitió priorizar la apertura de la capilla de san Hermenegildo con las necesidades litúrgicas requeridas y la obligada dignidad que merecía la memoria del cardenal. Los interlocutores del cardenal o

Identité et memoire au Moyen Âge, Rome, 2014. Para la península Ibérica son de referencia los trabajos de M. J. Gómez Bárcena, M. Núñez Rodríguez, M. Cendón Fernández, O. Pérez Monzón, F. Español Bertrán y S. Morales Cano.

62 T. LAGUNA PAÚL, "Memoria funeraria y patronazgo de Juan de Cervantes en la catedral de Sevilla. Mercadante de Bretaña y las obras de la capilla de san Hermenegildo", en Obispos y catedrales. Arte en la Castilla Bajo Medieval. Simposio internacional celebrado en la Universidad de León, 25-27 octubre 2017. 
de la catedral acordarían desde el primer momento con Lorenzo Mercader el diseño completo del monumento funerario $y$, específicamente, las dimensiones del bulto, las características del paño rico, el número de emblemas heráldicos y de ángeles tenantes, de los tabernáculos y de las figuras que alojarían y de los leones del zócalo donde, años más tarde, Lorenzo Mercadante de Bretaña orgulloso de la obra realizada y, especialmente de la efigie del prelado, se vinculó con su firma a la memoria del cardenal (Fig. 10).

Concluidas y entregadas estas dos obras, la Virgen y el bulto del cardenal, que suponen el comienzo de los encargos documentados a Lorenzo Mercader para la capilla de san Hermenegildo y la apertura de

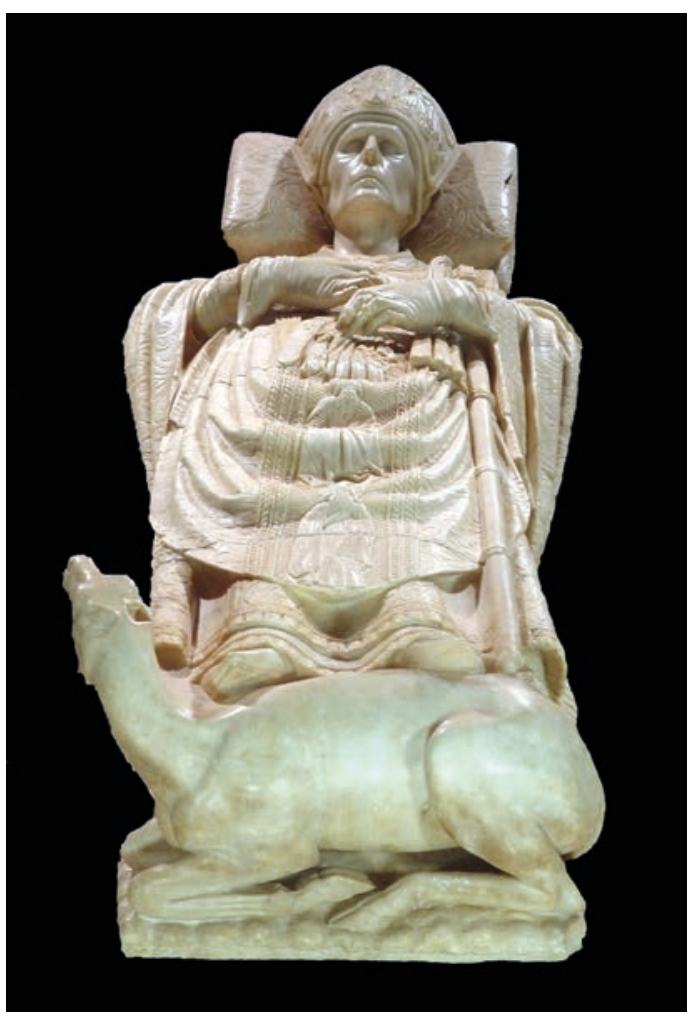

- Fig. 10. Lorenzo Mercader / Lorenzo Mercadante de Bretaña. Bulto del cardenal Juan de Cervantes visto desde los pies. 1454. Catedral de Sevilla, capilla de san Hermenegildo. Foto de la autora.

ésta, el escultor continuaría con los trabajos del monumento funerario al menos hasta 1458, cuando todavía le abonaron parte de algunos relieves. Transcurrido los años ne- cesarios para la descomposición del cadáver, terminado completamente el monumento, desmontarían los tabiques del enterramiento provisional y, después de colocar el zócalo de alabastro, en el centro de la capilla, sobre la solería de ladrillo construyeron sobre éste el núcleo de mampostería, envolviendo la urna con los restos óseos del cardenal, que constituye el alma interior para el montaje de los relieves, de las hornacinas y la tapa del mantel con la inscripción que perpetúa las virtudes y grandeza del difunto donde apoya directamente la escultura funeraria terminada en 1454. Durante estos años la catedral realizó otros cambios en la capilla y sustituyó la Virgen tallada por este escultor por un retablo que, citado por las fuentes del siglo XVII, conformó la terminación definitiva de la capilla gótica de san Hermenegildo, la memoria perpetua del cardenal Juan de Cervantes en la catedral de Sevilla.

Para finalizar y como síntesis de lo expuesto en esta investigación queda demostrada la presencia de Lorenzo Mercader en la catedral de Sevilla desde 1453 cuando el cabildo le encargó dos esculturas de alabastro para la capilla funeraria del cardenal Juan de Cervantes: una Virgen y el bulto de este prelado que constituye, a su vez, la primera entrega de su monumento funerario. La inhumación temporal del cardenal, los testimonios de la urna con sus restos óseos descarnados y el carácter de los pagos conservados parecen confirmar un diseño y encargo unitario del monumento funerario pero dilatado cronológicamente, al menos, durante cuatro años. La naturaleza de la documentación ha permitido, igualmente, dar a conocer otros aspectos inéditos de la contabilidad de la catedral de Sevilla en 1454.

\section{BIBLIOGRAFÍA}

ADAMS, A. y BARKER, J., Revisiting the monument. Fifty years since Panofsky's Tomb Sculpture, London, 2016.

ALONSO MORGADO, J., Prelados sevillanos o episcopologio de la S.I.M.yP. de Sevilla, Sevilla, 1899-1904. 
ALONSO RUIZ, B., "El maestro de obras catedralicio en Castilla en el siglo XV", Anales de Historia del Arte, no 22 especial, 2012, pp. 225-243.

ÁLVAREZ MÁRQUEZ, C., Manuscritos localizados de Pedro Gómez Barroso y Juan de Cervantes, arzobispos de Sevilla, Alcalá de Henares, 1999.

ANGULO IÑIGUEZ, D., "Sepulcro del cardenal Cervantes en la catedral de Sevilla", en La Escultura en Andalucía, Sevilla, 1928, vol. I.

"Bordados de estilo eyckiano del sepulcro del cardenal Cervantes de la Catedral de Sevilla", Mélanges Hulin de Loo, 1931, pp. 1-4.

ARQUILLO TORRES, F., "El estado de conservación de las esculturas de Mercadante que decoran las portadas del bautismo y del nacimiento de la catedral de Sevi1la", Atrio: revista de arte, no 2, 1990, pp. 145-158.

AZCÁRATE, J. M. de, Colección de documentos para la Historia del Arte en España 2. Datos histórico-artísticos de fines del siglo XV y principios del XVI, Zaragoza, 1982.

BAUDOIN, J., “Destinées itinerantes des grands imaginiers de la fin du moyen âge", Francia. Forschungen zur westteuropäischen Geschichte, vol. 14, 1986 (1987), pp. 163-164.

La sculpture flamboyante en Normandie et Ile-de-France, Paris, 1993.

BOCK, N., FOLETTI, I. y TOMASI, M., L'évêque, l'image et la mort. Identité et memoire au Moyen Âge, Rome, 2014.

CASSARD, J. C., “Un Valencien en Bretagne au XVe siècle: Vincent Férier (1418-1419), 3n HAL France p. 167, consultado el 18 de septiembre de 2016. URL: http://hal.univbrest.fr/hal-00439427.

CEÁN BERMÚDEZ, J. A., Diccionario histórico de los mas ilustres profesores de las bellas artes en España, Madrid, 1800, vol. III.
Descripción artística de la catedral de Sevilla, Sevilla, 1804.

CIRUJANO GUTIÉRREZ, C., "Proceso de intervención en las portadas del Nacimiento y del Bautismo de la catedral de Sevilla", Bienes Culturales, $\mathrm{n}^{\mathrm{o}}$ 1, 2002, pp. 101-120.

ESPAÑOL BERTRÁN, F., “El artífice y sus habilidades. La transmisión del conocimiento artístico medieval", en $\mathrm{M}$. MIQUEL, O. PÉREZ MONZON y $\mathrm{M}$. BUESO, Ver y crear. Obradores y mercados pictóricos en la España gótica (1350-1500), Madrid, 2016, pp. 98-134.

GESTOSO y PÉREZ, J., Sevilla monumental $y$ artística. Historia y descripción de todos los edificios notables, religiosos y civiles que existen actualmente en esta ciudad y noticia de las preciosidades artísticas y arqueológicas que en ellos se conservan, Sevilla, 1890, T. II.

Ensayo de un diccionario de los artífices que florecieron en Sevilla desde el siglo XIII al XVIII inclusive, Sevilla, 1899, vol. I.

GÓMEZ-FERRER LOZANO, M., “La cantería valenciana en la primera mitad del XV: El Maestro Antoni Dalmau y sus vinculaciones con el área mediterránea", Anuario del Departamento de Historia y Teoría del Arte, no 9-10, 1997-1998, pp. 91-106.

El maestro de la catedral de Valencia Antoni Dalmau (1435-1453), consultado el 18 de mayo de 2016. URL: http://www.academia.edu/11010998/.

GÓMEZ MORENO, M., “¿Jooskén de Utrech, arquitecto y escultor?", Boletin de la Sociedad Castellana de Excursiones, V, 1911, pp. 63-66.

GONZALEZ CARAVALLO, J., "Escultura en Sevilla en tiempos de Siloé: una nueva obra para el catálogo", en J. YARZA y A. IBAÑEZ (coords.), Actas del Congreso Internacional sobre Gil Siloé y la Escultura de su época, 1999, Burgos, 2001, pp. 487-499.

GOÑI GAZTAMBIDE, J., “Cervantes, Juan de", en Diccionario de Historia Eclesiástica 
de España, Suplemento I, Madrid, 1987, pp. 124-128.

HERRERA DÁVILA, J., El Hospital del cardenal de Sevilla y el doctor Hidalgo Agüero: visión histórico-sanitaria del Hospital de san Hermenegildo de Sevilla (1445-1837), Sevi1la, 2010.

IBÁÑEZ FERNÁNDEZ, J., "La arquitectura en el reino de Aragón entre el Gótico y el Renacimiento: inercias, novedades y soluciones propias", en M. I. ÁLVARO ZAMORA y J. IBAÑEZ FERNÁDEZ (coords.), La arquitectura en la Corona de Aragón entre el Gótico y el Renacimiento (1450-1550). Rasgos de unidad y diversidad, Zaragoza, 2009, pp. 39-95.

- La capilla del palacio arzobispal de Zaragoza en el contexto de la renovación del Gótico final en la Península Ibérica, Zaragoza, 2012.

IBÁÑEZ FERNÁNDEZ, J. y ANDRÉS CASABÓN, J., La catedral de Zaragoza de la Baja Edad Media al primer quinientos. Estudio documental y artístico, Zaragoza, 2016.

IBÁÑEZ FERNÁNDEZ, J. y DOMÍNGUEZ MONTERO, D., "Antes de Sevilla: Lorenzo Mercader (Mercadante) de Bretaña en Zaragoza (1446-1448). Transferencias e intercambios entre las Coronas de Aragón y Castilla a mediados del siglo XV", Artigrama, no 30, 2015, pp. 169-191.

JENNINGS, N., “Lorenzo Mercadante de Bretaña, primus inter pares of Northern European sculptors in fifteenth-century Castille", en N. JENNINGS y T. LAGUNA, Lorenzo Mercadante de Bretaña. Virgen del Buen Fin, Madrid, 2016, pp. 13-44.

JENNINGS, N. y LAGUNA PAÚL, T., Lorenzo Mercadante de Bretaña. Virgen del Buen Fin, Madrid, 2016.

JIMÉNEZ MARTÍN, A., "Las fechas de las formas", en La catedral de Sevilla. Fundación y fábrica de la obra nueva, Sevilla, 2006, pp. 15-114.

"Rarezas de la capilla de la Antigua", en La piedra postrera. V centenario de la conclu- sión de la catedral de Sevilla, (2) comunicaciones, Sevilla, 2007, pp. 401-420.

Anatomía de la catedral de Sevilla, Sevilla, 2013.

"La catedral de Sevilla y el gótico mediterráneo", en B. ALONSO y F. VILLASENOR, Arquitectura tardogótica en la Corona de Castilla: trayectorias e intercambios", Santander, 2014, pp. 179-200.

JIMÉNEZ MARTÍN, A. y PÉREZ PEÑARANDA, I., Cartografía de la Montaña Hueca, Sevilla, 1997.

JIMÉNEZ SANCHO, A. y JIMÉNEZ MARTÍN, A., "La restauración del sepulcro del cardenal Cervantes de la catedral de Sevilla", en En el umbral de la memoria. Actas de las XIII jornadas internacionales de intervención en el patrimonio histórico-artístico, (COAR, Logroño, 3-6 noviembre 2055), Logroño, 2005, pp. 305-315.

LACARRA, M. C. (coord.), El retablo mayor de San Salvador de Zaragoza, Zaragoza, 2000.

LAGUNA PAÚL, T., “Las portadas del Bautismo y del Nacimiento de la catedral de Sevilla", Bienes Culturales, Revista del Patrimonio Histórico Español, nº1, 2002, pp. 83-101.

"Llegada y primeras obras de Miguel Perrin en la catedral de Sevilla: el programa escultórico de la reconstrucción del cimborrio de Juan Gil de Hontañón”, Laboratorio de Arte, no 24, 2012, pp. 137-162.

“De la línea al volumen: génesis figurativa y modelos grabados en la obra de Lorenzo Mercadante de Bretaña", en Copia e invención. Modelos, réplicas, series y citas en la escultura europea, II Encuentro internacional de museos y colecciones de escultura, Valladolid, 2013, pp. 137-150.

"Marco arquitectónico y retórica visual en barro en la catedral de Sevilla", en B. ALONSO RUIZ y J.C. RODRÍGUEZ ESTEVEZ, Sevilla 1514. Arquitectos tardogóticos en la encrucijada, Sevilla, 2016, pp. $39-48$. 
"The Virgen del Buen Fin in the context of the sculptural oeuvre of Lorenzo Mercadante de Bretaña", en N. JENNINGS y T. LAGUNA, Lorenzo Mercadante de Bretaña. Virgen del Buen Fin, Madrid, 2016.

"Memoria funeraria y patronazgo de Juan de Cervantes en la catedral de Sevilla. Mercadante de Bretaña y las obras de la capilla de san Hermenegildo", en Obispos y catedrales. Arte en la Castilla Bajo Medieval (en prensa).

LÓPEZ LORENTE, V. D., "Las 'mostres imayges e empints' de Rotllí Gautier (doc. 1392-1441) y su importancia en la transmisión del conocimiento artístico", en B. ALONSO RUIZ y J. C. RODRÍGUEZ ESTÉVEZ, Arquitectos tardogóticos en la encrucijada, Sevilla, 2016, pp. 79-89.

MARTÍN SÁNCHEZ, M. A., El imaginero Lorenzo Mercadante. Estudio de la obra y claves de su huella en la Virgen de las Nieves de la Isla Canaria de la Palma, La Laguna-Tenerife, 2009.

MARTÍNEZ, R., "Gómez Díaz de Burgos (1430-1466), maestro mayor de la obra de la catedral de Palencia", Publicaciones de la Institución Tello Téllez de Meneses, $\mathrm{n}^{\mathrm{o}}$ 58, 1988, pp. 417-426.

MONTES ROMERO-CAMACHO, I., "LOS recursos financieros de la 'Obra' de la catedral de Sevilla durante el reinado de Enrique IV de Castilla (1454-1474). Los libros de fábrica", en A. JIMÉNEZ MARTÍN (coord.), La catedral después de Carlin. XVII Aula Hernán Ruiz, Sevilla octubre 2010, Sevilla, 2010, pp. 77-137.

OLLERO PINA, J. A., "Los mayordomos de la fábrica de la catedral en el siglo XV (1411-1516)", en A. JIMÉNEZ (coord.), La catedral entre 1434 y 1517: historia y conservación. XX edición del Aula Hernán Ruiz, Sevilla, 2013, pp. 125-161.

Juan de Cervantes (1382-1453), "el mayor perlado de mis Regnos", original en prensa.

PÉREZ-EMBID WAMBA, J., "La obra del P. Quintanadueñas en el contexto ha- giográfico hispano", en A. QUINTANADUEÑAS, Santos de la ciudad de Sevilla y su arzobispado. Fiestas que su Santa Iglesia Metropolitana celebra (1637), Sevilla, 2006.

Culto funerario y registro cronológico de la catedral de Sevilla (siglos XIII-XV), Madrid, 2015.

PONZ, A., Viage de España en que se da noticia de las cosas mas apreciables y dignas de saberse, que hay en ella, Madrid, 1786, vol. IX.

REINA GIRÁLDEZ, F., “Llegada a Sevilla y primeras obras de Lorenzo Mercadante de Bretaña", Archivo Hispalense, no 215, 1987, pp. 143-151.

RÍOS COLLANTES DE TERÁN, I., “Bartolomé Sánchez: maestro mayor de carpintería de la obra de Santa María ( $i-1464)^{\prime \prime}$, en A. JIMÉNEZ MARTÍN (coord.), La catedral después de Carlin. XVII Aula Hernán Ruiz, Sevilla octubre 2010, Sevilla, 2010, pp. 5-27.

ROMERO MALDONADO, J., "Testamento del cardenal Cervantes", Boletín de la Real Academia sevillana de Buenas Letras, $\mathrm{n}^{\circ}$ 41, 1924, pp. 121-131.

SERRA DESFILIS, A., "Promotores, tradiciones e innovación en la arquitectura valenciana del siglo XV”, Goya, n⿳ 334, 2011, pp. 58-73.

STEGMANN, H. y ANGULO ÍNIGUEZ, D., La escultura en Occidente, Barcelona, 1936.

TEVA, M. A. (coord.), Lorenzo Mercadante de Bretaña: La escultura del arcángel San Miguel: Sanlúcar la Mayor, Sevilla, 2007.

VALERO MOLINA, J., "Pere Torregrosa, Pere Jalopa i la capella de san Sever de la catedral de Barcelona", Lambard. Estudis d'art medieval vol. XXI, 2010, pp. 172-175.

YARZA LUACES, J., "Hombres de poder, gentes del libro, "Viri Litterati" y encargos artísticos", El marqués de Santillana (1398-1458), los albores de la España Moderna. El humanista. Catálogo de la exposición, Hondarribia, 2009, pp. 9-34. 
YUSTE GALÁN, A., “La introducción del arte flamígero en Castilla: Pedro Jalopa, maestro de los Luna", Archivo Español de Arte, no 307, LXXVI, 2004, pp. 291-300. 